\title{
RMetS
}

Royal Meteorological Society

\section{Cold-pool formation in a narrow valley}

\author{
S. B. Vosper, ${ }^{a \star}$ J. K. Hughes, ${ }^{b}$ A. P. Lock, ${ }^{a}$ P. F. Sheridan, ${ }^{a}$ A. N. Ross, ${ }^{b}$ B. Jemmett-Smith ${ }^{b}$ \\ and A. R. Brown ${ }^{\mathrm{a}}$ \\ ${ }^{\mathrm{a}}$ Met Office, Exeter, UK \\ ${ }^{\mathrm{b}}$ University of Leeds, UK
}

${ }^{\star}$ Correspondence to: S. B. Vosper, Met Office, FitzRoy Road, Exeter EX1 3PB, UK.

E-mail: simon.vosper@metoffice.gov.uk

\begin{abstract}
A numerical model simulation of the formation of a cold pool within a narrow valley during a clear calm night is presented. The results are compared with measurements made during the COLd air Pooling EXperiment (COLPEX). It is demonstrated that the model provides a realistic simulation of the observed cold pool. The cold pool begins to form approximately 1.5 hours before sunset, when the near-surface air within the valley starts to cool more rapidly than the air on the surrounding hills. The model potential temperature budget is used to determine which physical processes are most important for the evolution of the cold pool. The results show that sheltering provided by the valley causes a turbulent heat flux divergence over the lowest $5 \mathrm{~m}$ above the valley floor, which is large compared with the other terms in the budget. This causes relatively rapid cooling of the air adjacent to the ground. On the surrounding hills the turbulent heat flux divergence is larger than in the valley, but the enhanced cooling this provides is approximately balanced by an almost equally large warming tendency from advection. The net effect of these two terms is small compared with that in the valley and therefore the cooling rate is smaller. Above $5 \mathrm{~m}$, the cooling in the valley is dominated by local transport of cold air away from the surface into the interior valley atmosphere.
\end{abstract}

\footnotetext{
Key Words: COLPEX; stable boundary layer; sheltering; drainage flow; orography

Received 21 August 2012; Revised 1 March 2013; Accepted 18 March 2013; Published online in Wiley Online Library 19 June 2013

Citation: Vosper SB, Hughes JK, Lock AP, Sheridan PF, Ross AN, Jemmett-Smith B, Brown AR. 2014. Cold-pool formation in a narrow valley. Q. J. R. Meteorol. Soc. 140: 699-714. DOI:10.1002/qj.2160
}

\section{Introduction}

An improved understanding of the behaviour of the stable boundary layer (SBL) in complex terrain is important for a number of reasons. Air and surface temperatures, humidity and winds can vary rapidly on the small scales associated with the SBL. The details of high-impact weather such as fog, ice and air pollution remain unresolved by current numerical weather prediction (NWP) models. Post-processing techniques (Sheridan et al., 2010) can be used to add local subgrid detail to NWP forecasts, but these require an understanding of the key small-scale phenomena in order to improve the forecasts consistently. The boundary-layer parametrizations used in NWP and climate models are also known to be deficient under strongly stable conditions (Cuxart et al., 2006). The extent to which surface inhomogeneities can influence the transport of heat, momentum and moisture at unresolved scales is an important question for the design of turbulence parametrization schemes (McCabe and Brown, 2007). Understanding the local impact of climate change in mountainous regions (Pepin and Seidel, 2005) also requires knowledge of how small-scale processes depend on largerscale weather conditions.

One particular SBL phenomenon that is poorly understood is the occurrence of cold pools in valleys. On clear calm nights, relatively cold air temperatures can be found in the bottom of valleys. In extreme circumstances, such 
as those which occur in closed sink holes, the temperature deficits may be as large as a few tens of degrees (Whiteman et al., 2001; Clements et al., 2003; Zängl, 2005a). Depending on the synoptic weather patterns and radiative heating, cold pools may either be eroded during the day or can persist for long periods. In urban areas, such as the Salt Lake basin, USA, the build-up of pollutants in persistent cold pools can cause significant health problems.

Although widely observed, the mechanisms by which cold pools form are not well understood. For example, katabatic or drainage flows are sometimes cited as the cause of cold pools (see, for example, the discussion by Bodine et al., 2009), yet the extent to which they play a major role in the temperature budget at the bottom of a valley is not clear. Drainage flows occur when the radiative heat loss of sloping surfaces causes air in the surface layer to cool to temperatures that are lower than those of the adjacent air, away from the slope at the same height. The resulting horizontal buoyancy gradient drives a flow in the downslope direction, transporting air toward the valley bottom. In complex valley systems, drainage flows may be generated in different individual tributary valleys and these can join up to form a deeper drainage current, which flows along the main valley. There have been several observational studies of drainage flows in the river catchments of mountainous regions (Barr and Orgill, 1989; Neff and King, 1989; Gudiksen et al., 1992; LeMone et al., 2003) and also in modest valleys with only very shallow slopes (Mahrt et al., 2001). Recent measurements and modelling of cold-pool behaviour within the Meteor Crater, Arizona, USA (Whiteman et al., 2008, 2010; Haiden et al., 2011; Kiefer and Zhong, 2011) have highlighted the importance of regional-scale drainage flows, which can occur across the slopes surrounding basins and valleys. Intrusion of air from such flows into the cold pool can affect the vertical temperature structure. In the case of the Meteor Crater, this results in the development of an isothermal layer above the surface inversion. More generally, however, the contribution to the temperature budget from advection in drainage flows will depend crucially on the along-slope temperature gradient. As discussed by Bodine et al. (2009), this temperature gradient can have either sign, implying that both warming and cooling could be associated with drainage flows. Further, it is not clear that the transport of cold air down the valley slopes should, by itself, result in lower temperatures at the valley bottom than on the surrounding slopes. In fact some numerical simulations (Zängl, 2005b) have shown how drainage flows can act to weaken cold pools. When the flows are orientated along the direction of the synoptic-scale pressure gradient, the cold air can drain more easily down the valley, thus reducing the lifetime of the cold pool.

There have also been several studies in which in situ cooling within the valley is cited as the cause of the cold pools. For example, Thompson (1986) has shown that cold air pools can form in valleys without any drainage flow. Gustavsson et al. (1998) observed pockets of cold air during calm clear nights in the absence of drainage flow but where, due to undulations in the terrain or the presence of trees, there was a localized sheltering effect. The study contained examples where valleys as shallow as $10 \mathrm{~m}$ appeared to promote drops in air temperature larger than $7 \mathrm{~K}$ on clear and calm nights. This sheltering mechanism relies on the reduction of turbulent mixing of warmer air from aloft with the cold near-surface air. Under clear-sky conditions, this leads to a higher rate of cooling of the air close to the radiatively cooling surface. The turbulence tends to be reduced in dips in the terrain, within valleys or in forested areas and will be relatively stronger in exposed areas. The spatial differences in cooling rates result in localized cold pools, which usually develop a short time after sunset.

The recent observations by Bodine et al. (2009) of temperature variations along a gentle slope strongly suggest that sheltering was responsible for cold-pool formation in a small depression surrounded by trees. The measurements also suggested that drainage flows were not important in the cold-pool heat budget and that if they had penetrated the cold pool they would have contributed a warming effect, which was not observed. Vosper and Brown (2008) used a series of simple idealized numerical simulations to examine how changes in valley depth and boundary-layer wind and stability would influence cold-pool strength. Again, this study demonstrated that the cold pools formed as a result of reduced downward turbulent heat flux when the flow within the valley was sheltered relative to that outside. The study was restricted to two-dimensional (2D) valleys, however. Realistic three-dimensional (3D) valley shapes were not considered, although Smith et al. (2009) demonstrated that the same mechanism was likely to be important in real complex terrain.

The valley considered in this study is the Clun Valley, Shropshire, UK. This was the site of a recent field experiment: the COLd-air Pooling EXperiment (COLPEX), described by Price et al. (2011). Sheridan et al. (2013) have studied the properties of the cold pools observed during COLPEX as a function of synoptic conditions and demonstrate how they behave in a similar way to those in the simple 2D valleys simulated by Vosper and Brown (2008), in which local sheltering was the primary mechanism for coldpool development. Both studies suggest that the cold-pool strength, expressed as the maximum night-time temperature differences between the valley bottom and the surrounding hills, is to a large degree controlled by the non-dimensional valley depth, $N H / U$, where $H$ is the valley depth and $U$ and $N$ are the night-time average low-level wind speed and buoyancy frequency outside the valley, respectively. The cold-pool strength increases with $\mathrm{NH} / U$, suggesting that stronger stability enhances the sheltering effect, but for sufficiently large values $(\gtrsim 1)$ the flow within the valley becomes decoupled from that outside. The cold-pool strength is then independent of $N H / U$.

Whilst there can be no doubt that drainage is an important aspect of the flow in stable conditions, it seems unlikely that in general it can be the principal cause of cold pools within valleys. A different process, such as the above sheltering mechanism, is required. The purpose of this study is to determine how cold pools form in the Clun Valley and to assess the extent to which they can be explained by sheltering alone. The importance of other competing mechanisms, such as radiative cooling and advection, will be examined. Note that the analysis of the COLPEX observations presented by Sheridan et al. (2013) does not include an in-depth investigation into the processes controlling cold-pool formation. An analysis of the coldpool heat budget, and in particular the turbulent heat-flux divergence, was not undertaken. This is primarily because of the difficulty of quantifying the other important terms. Local advection, for example, is difficult to estimate even with 
a high-resolution observing network. As demonstrated in section 5 , advection is important in numerical simulations. The turbulent heat-flux divergence cannot be considered in isolation.

In this study, numerical simulations are used to examine the heat budget in the Clun Valley. The remainder of the article is set out as follows. Sections 2 and 3 provide brief descriptions of the field experiment and model, respectively. A simulation of a clear-sky stable case is presented in section 4, along with a comparison of the model results with the observations. The potential-temperature budget is examined in section 5 . The results are summarized and conclusions are drawn in section 6.

\section{The COLPEX experiment}

The COLPEX study was conducted in and around the Clun Valley $\left(52.43^{\circ} \mathrm{N}, 3.14^{\circ} \mathrm{W}\right)$, Shropshire, UK. The project involved long-term detailed field measurements of boundary-layer flow in complex terrain. The experiment, described in detail by Price et al. (2011), was primarily concerned with characterizing and understanding the formation of cold-air pools and fog in valleys during stable night-time conditions. The Clun Valley has a roughly east-west orientation and hill-top to valley-floor depths between 75 and $150 \mathrm{~m}$. The valley width (measured peakto-peak) is between 1 and $3 \mathrm{~km}$. The land coverage is mostly pasture, with hedgerows and some woodland. A wide range of near-continuous ground-based measurements were made in and around the valley for a period of 15 months during 2009-2010. These included mean flow and turbulent flux measurements at the three main mast sites: Duffryn, located on the floor of the valley, Springhill, situated on the ridge to the south of the valley, and Burfield, within a separate valley to the south of the Clun Valley. The suite of instruments also included an array of Hobo temperature sensors and automatic weather stations, a Doppler lidar, radiation sensors and soil temperature probes. Measurements were made near-continuously with these instruments throughout the experiment. In addition radiosondes were launched during Intensive Observation Periods (IOPs) and an instrumented vehicle was available on a number of occasions. A map showing the terrain and locations of the measurement sites is presented in Figure 1.

The focus of this study is on the relatively straightforward clear-sky case observed during the IOP 16 on 4-5 March 2010. The weather was dominated by anticyclonic conditions over the UK during this case, resulting in clear skies and a light northeasterly breeze across the Clun area during the afternoon and early evening of 4 March. The sky remained clear throughout the night. The breeze increased in strength and turned northwesterly after 0000 UTC on 5 March.

\section{The numerical model}

The numerical model used was the Met Office Unified Model (MetUM). This model solves the non-hydrostatic, deepatmosphere equations of motion using a semi-implicit, semi-Lagrangian numerical scheme (Davies et al., 2005). The model uses a rotated latitude-longitude horizontal grid with Arakawa C staggering and a terrain-following hybrid-height vertical coordinate with Charney-Phillips staggering. A comprehensive set of physical parametrizations

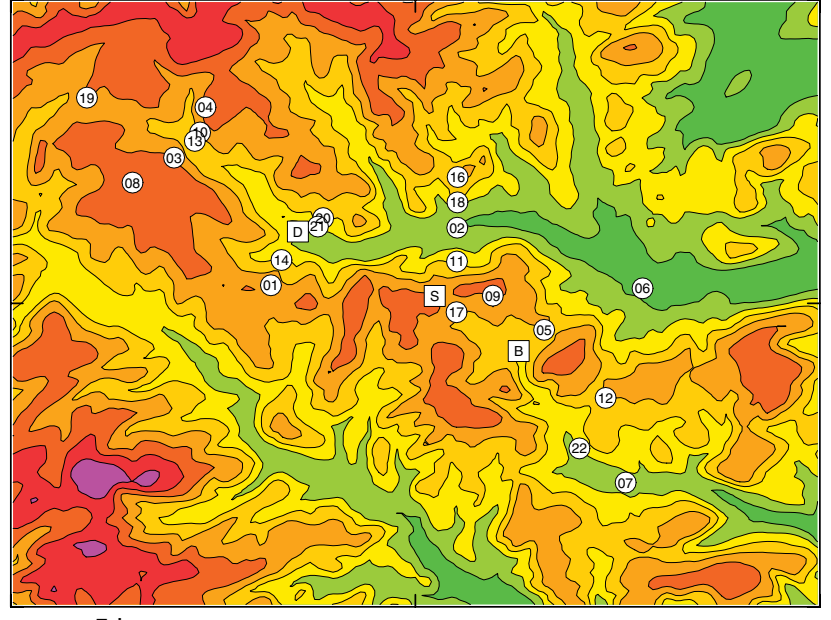

$5 \mathrm{~km}$

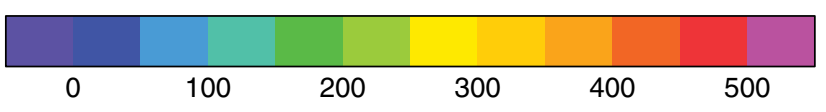

Figure 1. The terrain heights (in units of $\mathrm{m}$ ) in the vicinity of the Clun Valley and locations of the COLPEX measurement sites. The main sites are denoted with squares and labelled 'D' (Duffryn), 'S' (Springhill) and 'B' (Burfield). Circles mark the locations of the Hobo temperature sensors, with the numbers referring to the sensor number.

is used, including surface (Best et al., 2011), boundarylayer (Lock et al., 2000), mixed-phase cloud microphysics (Wilson and Ballard, 1999, extended to include optionally up to five condensed phase classes) and convection (Gregory and Rowntree, 1990, with additional downdraught and momentum transport parametrizations), though the convection scheme is not typically used for simulations with horizontal resolutions better than a few kilometres. The radiation scheme has recently been updated to include the effects of terrain aspect, shading and sky-view (Manners et al., 2011).

The simulations were conducted with a nested suite of model domains, the innermost of which had a horizontal resolution of $100 \mathrm{~m}$, with a size of $30 \times 30 \mathrm{~km}^{2}$ centred on the Clun Valley. In order to minimize lateral boundary effects, the variable horizontal resolution capability of the MetUM was used to enlarge this domain to approximately $80 \times 80 \mathrm{~km}^{2}$ by smoothly decreasing the resolution outside the regularly spaced central region towards $1.5 \mathrm{~km}$ at the boundaries. The grid spacing increased at a rate of approximately $5.5 \%$ per grid point within this stretching zone. The model used a source-orography dataset with $100 \mathrm{~m}$ resolution and $25 \mathrm{~m}$ resolution land-use data (Fuller et al., 1994).

The innermost model domain was nested inside a $1.5 \mathrm{~km}$ resolution model that covered the southern half of the UK. Simulations in the innermost domain were driven at the boundaries using Davies relaxation (Davies, 1976), using data taken every $10 \mathrm{~min}$ from the $1.5 \mathrm{~km}$ resolution model. Other than having a different horizontal grid and coverage, the configuration of the $1.5 \mathrm{~km}$ resolution model was identical to that of the Met Office UKV model, currently the highest resolution Met Office model configuration in operational use over the UK. This $1.5 \mathrm{~km}$ resolution model was driven with lateral boundary conditions from each threehour cycle of the operational Met Office $4 \mathrm{~km}$ resolution 3D-VAR analysis system. 


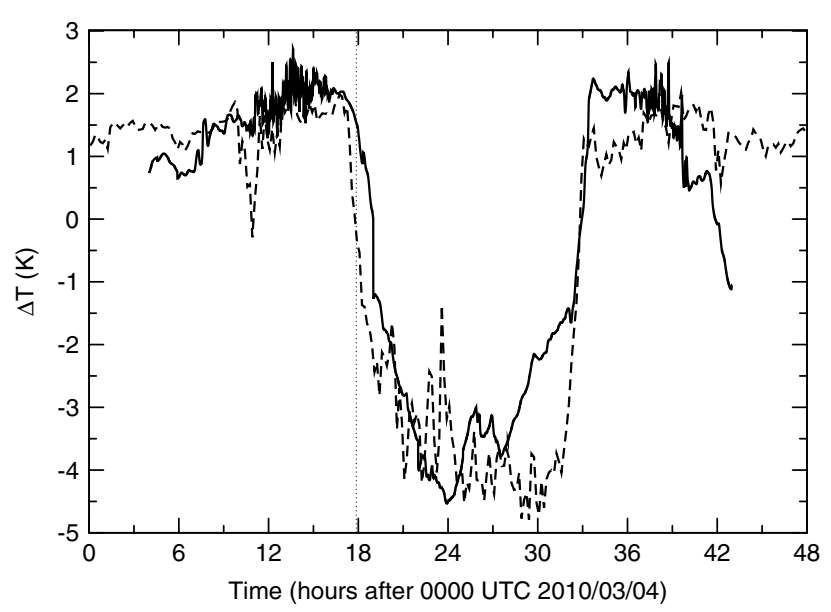

Figure 2. Time series of observed (dashed) and model (solid) differences in screen temperature between Duffryn and Springhill during IOP 16. The dotted line marks the time of local sunset at Springhill on 4 March 2010 (approximately 1757 UTC). The sampling intervals for the model and observations are 2 and $10 \mathrm{~min}$, respectively.

The configuration of the model in the inner $100 \mathrm{~m}$ resolution domain was very similar to that of the $1.5 \mathrm{~km}$ resolution model, though there were two notable differences. Firstly, enhanced vertical resolution was used in the inner domain. The grid consisted of 140 levels up to the model upper boundary at $40 \mathrm{~km}$, whereas 70 levels are used in the operational models. The vertical grid spacing increased quadratically with height, with 25 levels below $500 \mathrm{~m}$. The lowest grid level was placed at $2 \mathrm{~m}$ and the spacing between this and the adjacent level was $3.33 \mathrm{~m}$. This increased to $34 \mathrm{~m}$ at $433 \mathrm{~m}$. Sensitivity tests have shown that this enhanced resolution provides a better representation of the valley cold pools. Secondly, a 3D stability-dependent Smagorinsky-Lilly scheme was used to represent turbulent mixing in the inner domain, whereas the $1.5 \mathrm{~km}$ model uses a hybrid version of the scheme in which Smagorinsky-Lilly is only applied to horizontal mixing and vertical mixing is represented by the standard $1 \mathrm{D}$ boundary-layer scheme (Lock et al., 2000).

The simulation for IOP 16 was started at 0100 UTC on 4 March 2010 and ran for 42 hours, finishing at 1900 UTC on 5 March. Only model results for the innermost $(100 \mathrm{~m}$ resolution) domain are used in this study. Results for the coarser resolution outer domains are not considered.

\section{Model results}

\subsection{Cold-pool development and comparisons with observa- tions}

Many aspects of the simulation of the cold-pool development within the Clun Valley for IOP 16 appear to be realistic. For example, the predictions of the cold-pool strength, defined as the largest overnight differences between hill-top and valley temperature, are in good agreement with the observations. Figure 2 shows a time series of $\Delta T=T_{\mathrm{D}}-T_{\mathrm{S}}$, where $T_{\mathrm{D}}$ and $T_{S}$ are the screen-level $(1.5 \mathrm{~m})$ model temperatures at Duffryn and Springhill, respectively. Also shown are the observed temperature differences, measured at $1.2 \mathrm{~m}$. The model $\Delta T$ is in reasonable agreement with the observations. Starting approximately $1.5 \mathrm{~h}$ before sunset (local sunset at Springhill was approximately 1757 UTC), the model and observed $\Delta T$ begin to fall rapidly. By $1-2 \mathrm{~h}$ after sunset, $\Delta T$ becomes negative and continues to decrease over the following hours of the night until after midnight. There are differences in the details of the observed and modelled $\Delta T$ evolution, however. For example, some rapid fluctuations in $\Delta T$ are observed between 2100 and 0600 UTC that are not reproduced in the simulation. The model $\Delta T$ also increases from about 0300 UTC, whereas the observed negative temperature differences continue until 0600 UTC. Despite these differences, the minimum overnight values of $\Delta T$ are simulated with reasonable accuracy.

Figure 3 shows the model and observed $10 \mathrm{~m}$ wind speed and direction at the three main mast sites. At all sites, the model reproduces the observed trends in the flow to a reasonable degree. The diurnal cycle of wind speed is represented, with higher winds occurring during the daytime. The weak night-time winds at the valley sites (Duffryn and Burfield) relative to the hill site (Springhill) are also well represented. Arguably, the accuracy of the model wind speeds at both valley sites is remarkably good, although there is some underprediction of daytime winds at Burfield and the wind speeds at Springhill are somewhat overpredicted during both night and daytime. This could perhaps be connected with excessive (parametrized plus resolved) turbulent mixing or an inadequate representation of the surface roughness, although this has not been investigated. The model winds also show significant variability near Springhill and so the resolution and precise location of Springhill on the model grid may also contribute to these differences. The observed wind directions are reliably simulated at all three sites. For example, the change in flow direction from easterly during the afternoon through to westerly by midnight at Springhill is reproduced by the model. The rapid changes in wind direction at around 1800 UTC at both Burfield and Duffryn are also well simulated.

A more complete picture of the model performance for these cases can be obtained by looking at the structure of the cold pools using measurements across the valley. Figure 4 shows observed and model screen temperatures at sites located along two lines across the valley: one through Duffryn and another further east, through Hobo 02. The Duffryn cross-section consists of Hobos 20 and 21, the Duffryn site itself and Hobos 14 and 01. The cross-section to the east consists of Springhill and Hobos 11, 02, 18 and 16 (see Figure 1). The data shown are mean model and observed temperatures over consecutive $2 \mathrm{~h}$ intervals, before and after sunset (1757 UTC). As might be expected, before sunset both the model and measured temperatures are slightly higher in the valley than on the valley sides. In the period immediately following sunset $(0-2 \mathrm{~h})$ the observed temperature at Duffryn falls relatively rapidly as the cold pool forms. Consistent with the fact that the model $\Delta T$ falls slightly more slowly than observed (see Figure 2), the simulated rate of cooling at Duffryn relative to the valley sides is also less rapid. As the night progresses, the contrast in temperatures between Duffryn and the valley sides is less pronounced in the model, giving the model cold pool an appearance of being too broad. This is less noticeable on the eastern transect (Figure 4(b)), where the agreement is better, perhaps because the valley is wider here and better resolved by the model.

To summarize, comparisons between the model results and the observations suggest that, for the case considered 
(a)
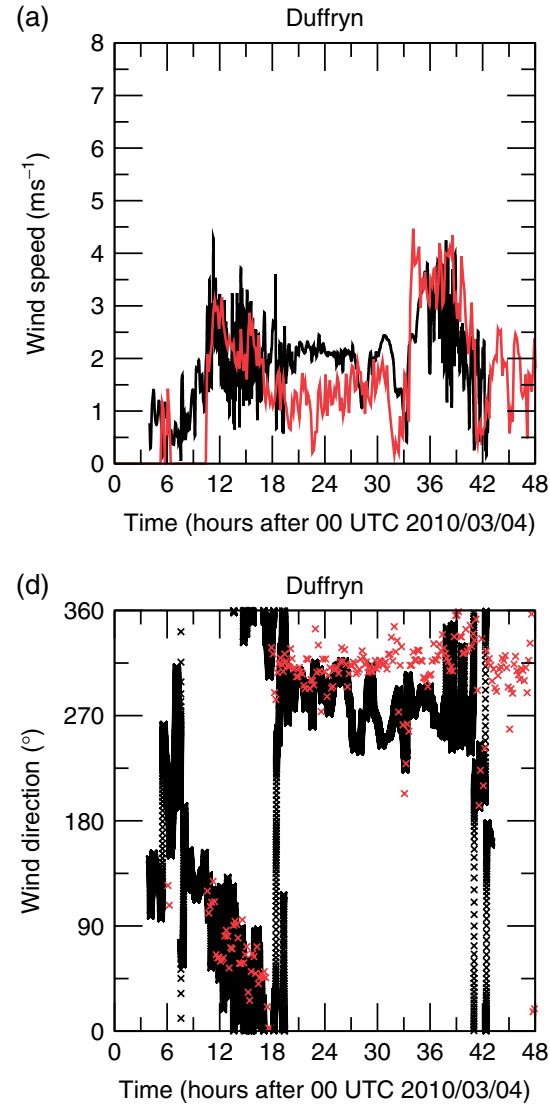

(b)

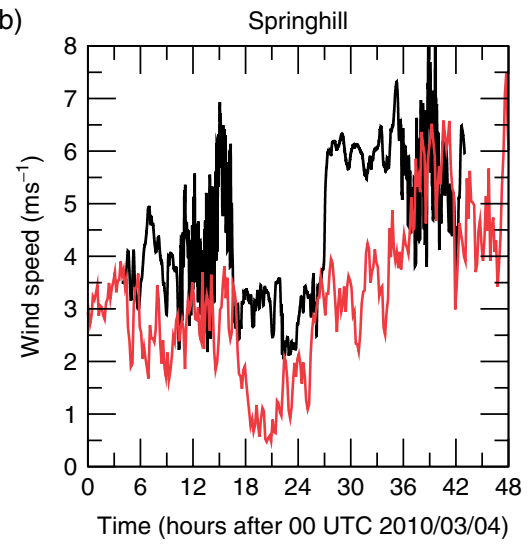

(e)

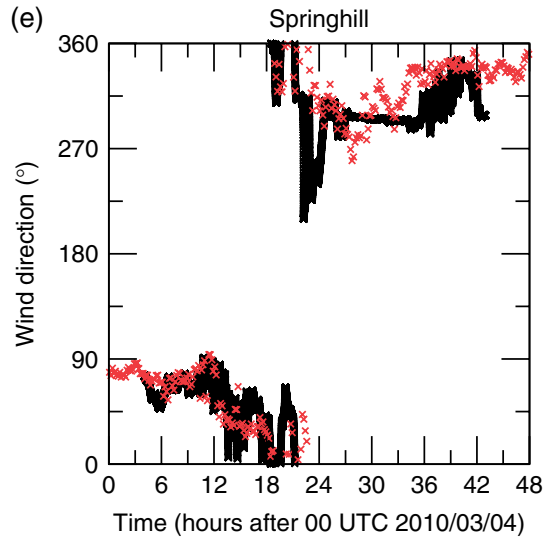

(c)

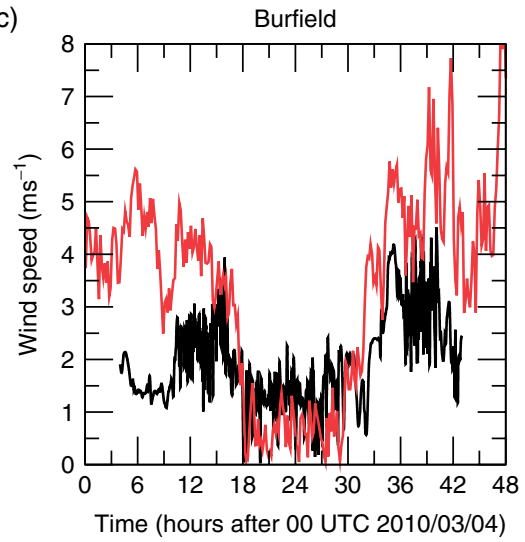

(f)

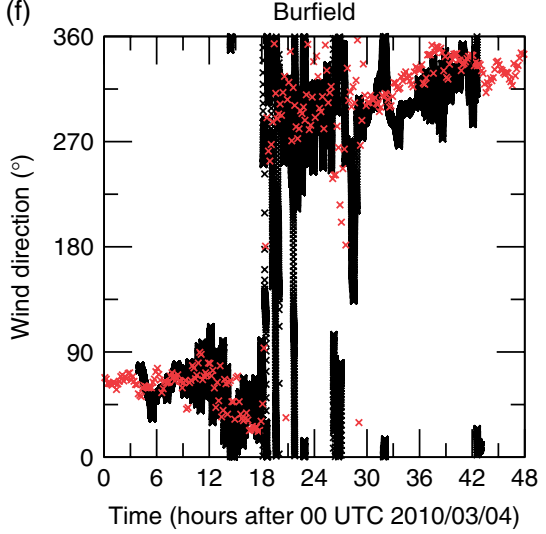

Figure 3. Time series of model (black) and observed (red) $10 \mathrm{~m}$ wind speed at (a) Duffryn, (b) Springhill and (c) Burfield during IOP 16. Panels (d), (e) and (f) show the $10 \mathrm{~m}$ wind direction at Duffryn, Springhill and Burfield, respectively.
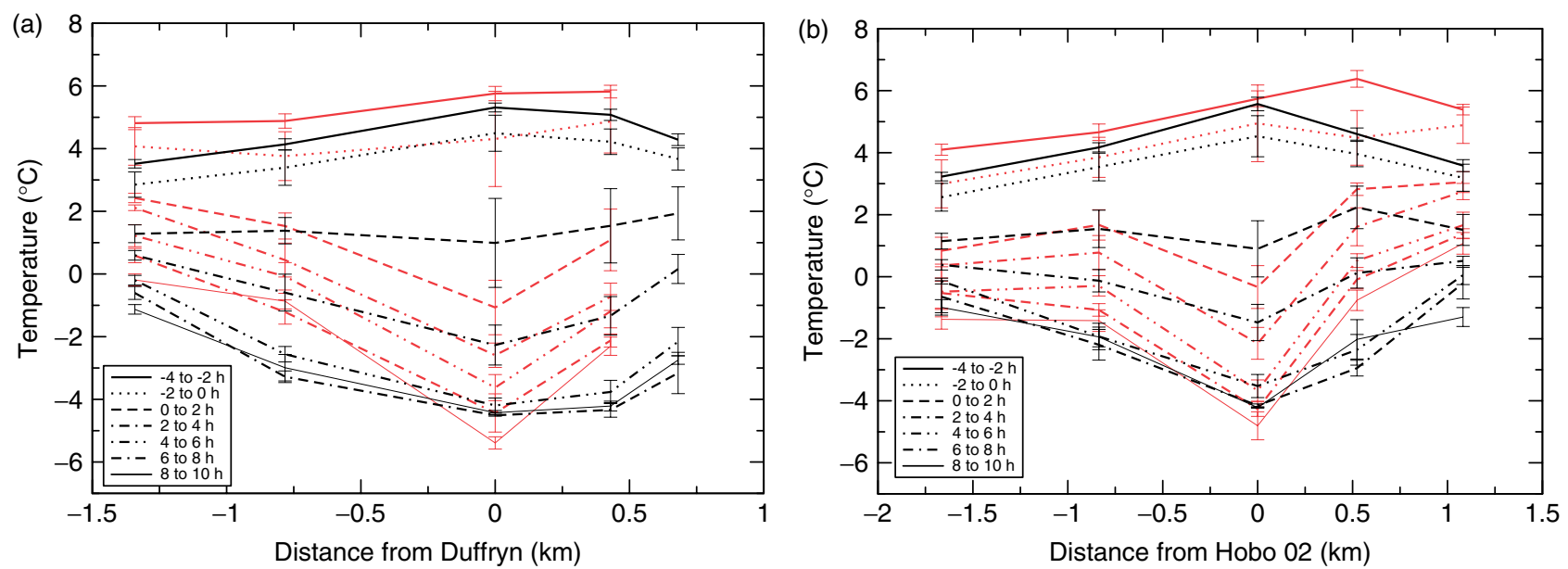

Figure 4. Cross-valley transects of $2 \mathrm{~h}$ mean screen temperatures at regular intervals during the night of IOP 16 . The cross-sections are constructed from model and observed data at (a) Hobo sites 20 and 21, Duffryn, Hobos 14 and 01 and (b) further east, using Springhill and Hobo sites $11,02,18$ and 16. The south side of the valley is to the left. Note that, due to a problem with the sensor, observations are missing from Hobo 20 for this case. The time intervals shown are relative to local sunset time at Springhill. Black lines denote the model predictions and red lines show the observations. The width of error bars denotes two standard deviations of the temperatures at each site during the $2 \mathrm{~h}$ periods.

here, the simulated cold pool is realistic. Whilst there are differences in some of the more detailed aspects of the model and observed cold-pool structure, the simulation is considered adequate for the purposes of understanding the processes involved in cold-pool development.

\subsection{Cold-pool evolution}

The simulated overnight potential temperature $(\theta)$ on the lowest model level $(2 \mathrm{~m})$ is shown in Figure 5 for IOP
16, along with the wind at $10 \mathrm{~m}$. To aid interpretation, hourly averaged fields are presented so that high-frequency variability is removed. The wind direction, in particular, becomes highly variable along the sheltered valley bottom as the cold pool develops. Time-averaging helps to elucidate the mean behaviour.

Figure 5 shows that between 1800 and 1900 UTC the $2 \mathrm{~m} \theta$ is approximately constant across the region. The $10 \mathrm{~m}$ winds are generally northeasterly across the hills, whereas within the sheltered valley the wind direction is more variable. 
(a)

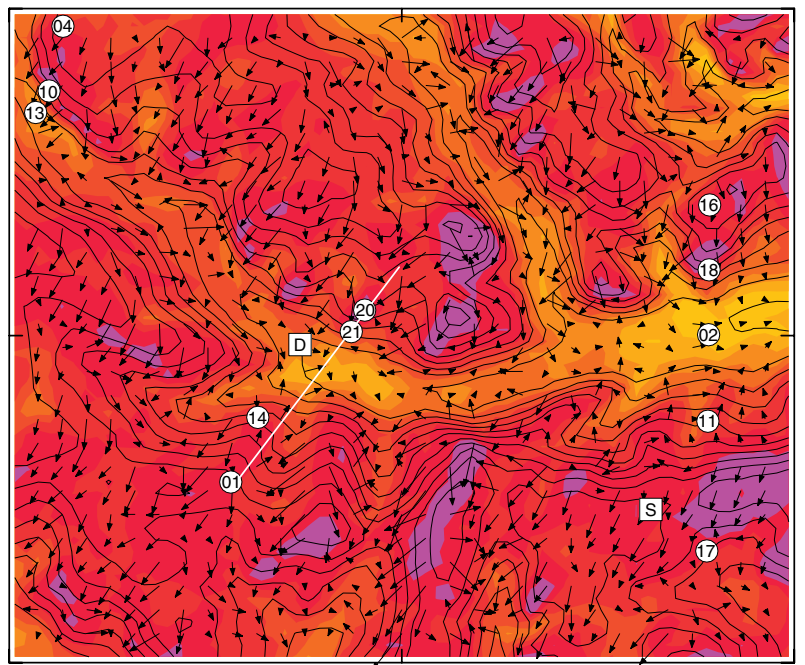

(c)

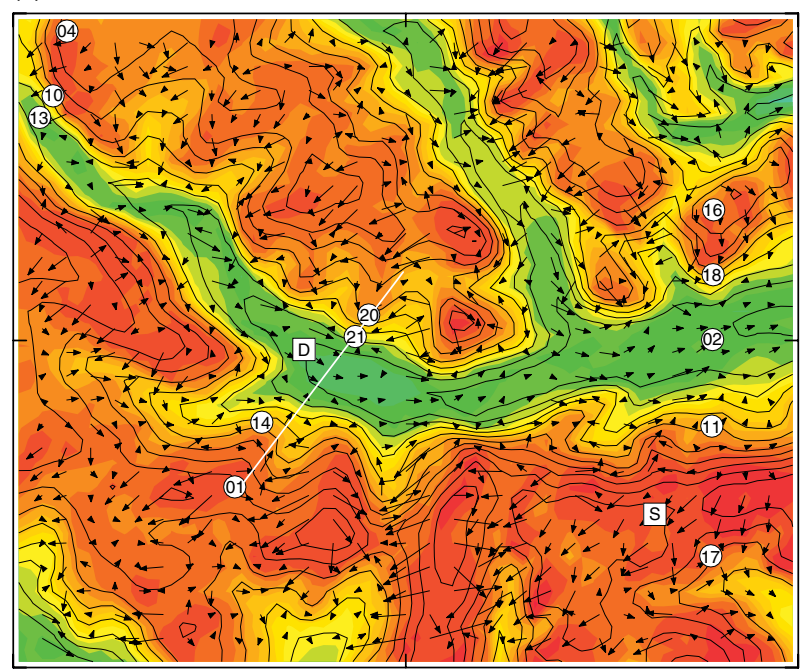

(e)
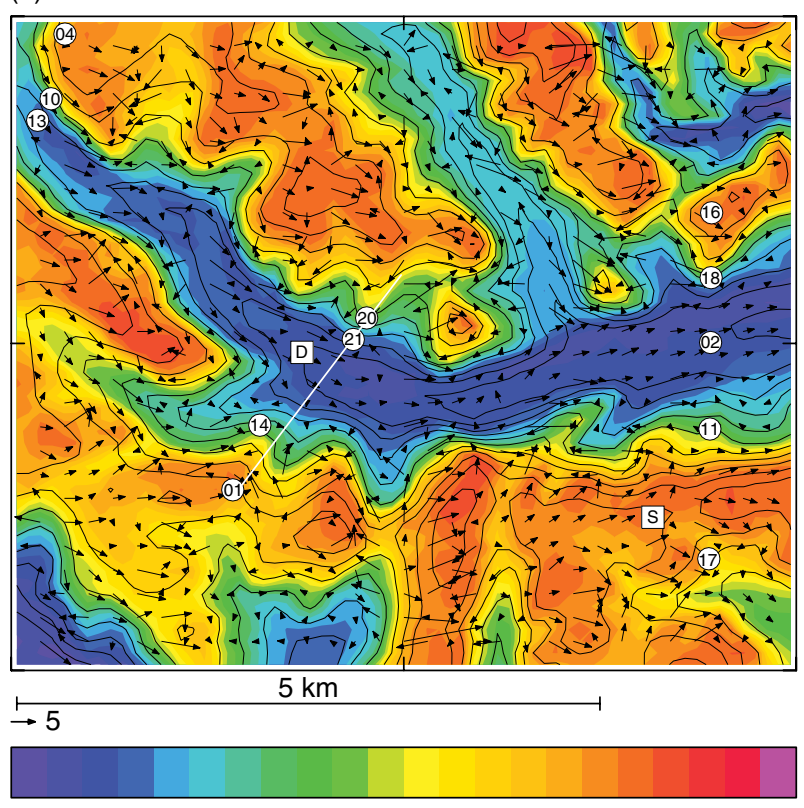

$-6$

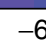

20100304 1800-1900

20100304 2000-2100

$201003042300-0000$ (b)

20100304 1900-2000

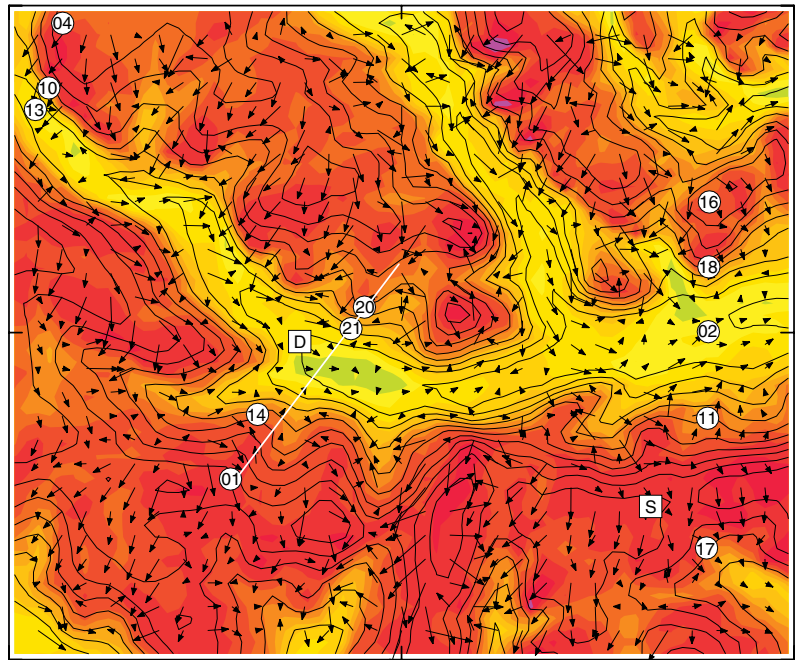

(d) $201003042100-2200$

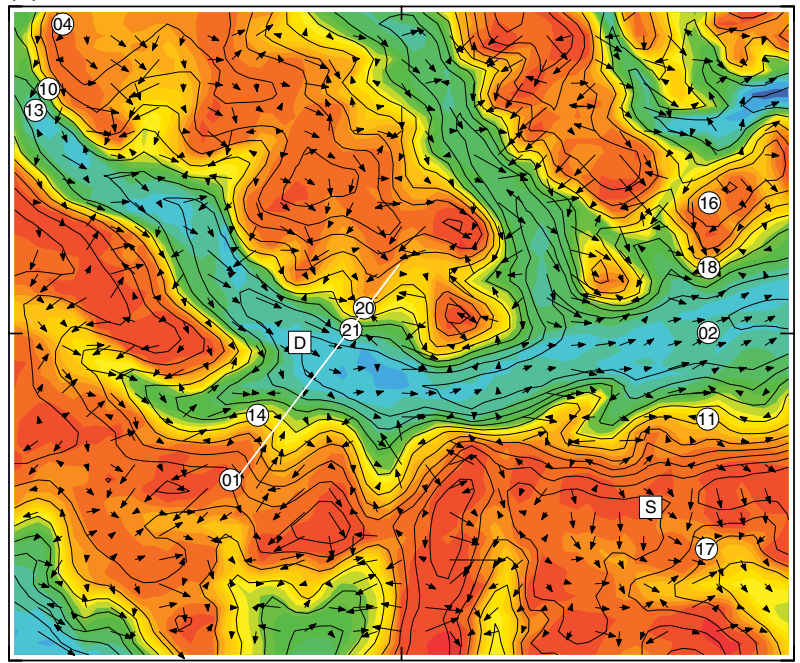

(f)

$201003050200-0300$
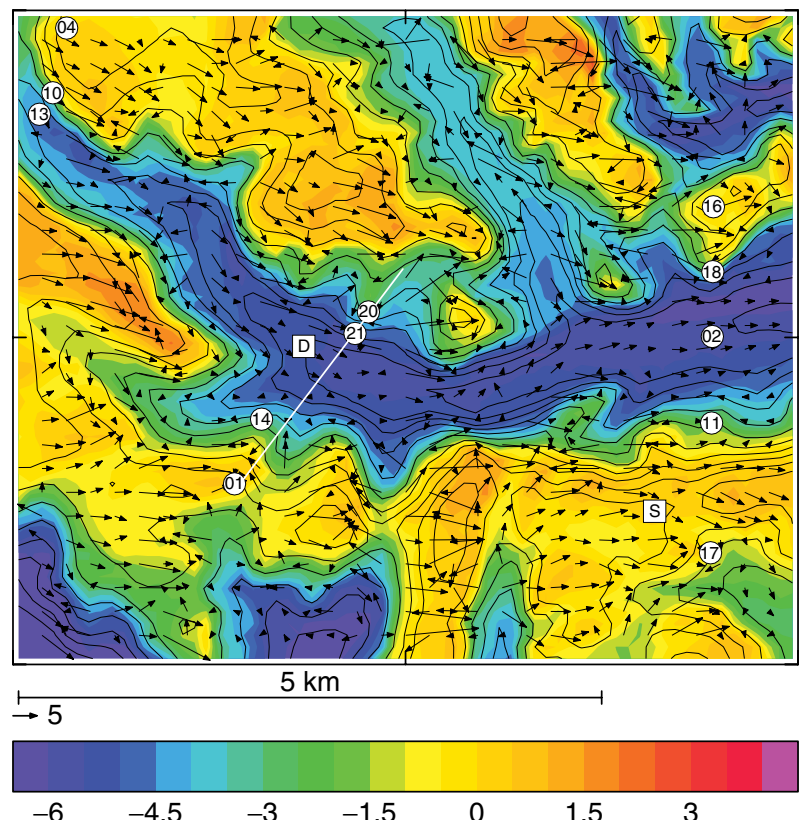

Figure 5. Model flow fields across the Clun Valley during IOP 16. Quantities shown are hourly mean $2 \mathrm{~m} \theta$ (colour shading, units ${ }^{\circ} \mathrm{C}$ ) and $10 \mathrm{~m}$ winds (vectors, units $\mathrm{m} \mathrm{s}^{-1}$ ) for (a) 1800-1900 UTC, (b) 1900-2000 UTC, (c) 2000-2100 UTC, (d) 2100-2200 UTC and (e) 2300-0000 UTC on 4 March and (f) 0200-0300 UTC on 5 March 2010. Line contours show the terrain heights (interval $20 \mathrm{~m}$ ). A key wind vector for a wind speed of $5 \mathrm{~m} \mathrm{~s}^{-1}$ is shown. The white line marks the orientation of the cross-sections shown in Figures 6 and 7. Note that only a portion of the innermost model domain is shown. 


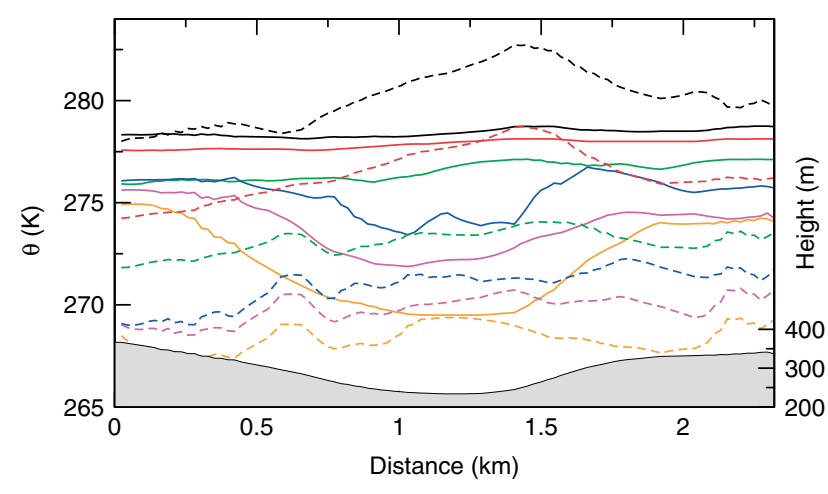

Figure 6. Simulated hourly mean potential temperature of the air at $2 \mathrm{~m}$ (solid lines) and the surface (dashed lines) along the cross-valley transect marked in Figure 5. Results are shown for the evening period of IOP 16 at 1300-1400 UTC (black), 1600-1700 UTC (red), 1700-1800 UTC (green), 1800-1900 UTC (blue), 1900-2000 UTC (magenta) and 2100-2200 UTC (orange). Grey shading denotes the terrain height along the transect. The southern end of the transect is on the left-hand side.

Close examination of Figure 5(a) reveals that some cold spots are already present on the valley floor at this time. The potential temperature is reduced in the eastern part of the valley and also in an area close to Duffryn. In some locations, there appears to be flow down the valley sides towards the valley bottom, suggestive of local drainage of relatively cold air from the slopes down into the valley. These local drainage currents are generally confined to the tributary valleys. By 1900-2000 UTC, the temperatures within the valley are already as much as $2{ }^{\circ} \mathrm{C}$ colder than on the hills. The valley-hill $\theta$ differences continue to increase as the night progresses. By 2100-2200 UTC, the air in the valley is typically $6{ }^{\circ} \mathrm{C}$ colder than across the hills. This difference has grown to around $7.5^{\circ} \mathrm{C}$ by $0200-0300$ UTC. Throughout the night, the winds remain relatively slack in the valley compared with those across the hills. Whilst the wind direction is quite variable, even after time averaging, it would appear that a westerly wind component develops along the bottom of the valley during the evening. This light down-valley current becomes most noticeable after 2000 UTC.

The evolution of the simulated $2 \mathrm{~m}$ potential temperature is shown in Figure 6 for the evening period along a crossvalley transect. Hourly mean results are shown. The crosssection is aligned approximately northeast-southwest, across the valley and close to Duffryn (see Figure 5). Also shown in Figure 6 are the hourly mean surface potential temperatures. Between 1600 and 1700 UTC, there is very little variation in the $2 \mathrm{~m} \theta$ across the valley, whilst the surface potential temperatures are relatively warm within the valley. The highest surface temperatures are found on the northern (south-facing) side of the valley, presumably because of relatively high insolation in the late afternoon. By 1900-2000 UTC, the signature of the cold pool in the $2 \mathrm{~m} \theta$ is clear, with a marked reduction within the valley. The surface potential temperature variation is quite different from that of the air, with no clear minimum in the valley. Between 1600 and 1800 UTC, the surface temperature falls more rapidly inside the valley (and across the northern slope in particular) than outside. However, the cooling rate is not sufficient to reduce the higher initial temperatures to a minimum at the valley bottom. By 2100-2200 UTC, the surface temperature cross-valley variation is small and does not resemble that of the air temperature. This rather surprising result is examined in more detail later in this section. Note that by $2100-2200$ UTC the $2 \mathrm{~m} \theta$ values at the valley bottom have decreased to levels only marginally higher than the surface temperature. At this point, radiative transfer between the air and the ground will be small in the valley. This is confirmed later in section 5 .

Vertical cross-sections along the above transect are shown in Figure 7 at selected times. Hourly mean velocity and potential temperatures are shown. The velocity fields have been projected on to the vertical plane. Between 1700 and 1800 UTC (Figure 7(a)), the northeasterly flow sweeps down through the valley. The potential temperature is close to uniform, although a thin layer with lower temperatures appears to have formed on the southern valley side. These lower temperatures are linked to slightly reduced surface temperatures (see Figure 6), a result of reduced incoming solar radiation on the north-facing slopes in the late afternoon.

By 1800-1900 UTC (Figure 7(b)), a thin drainage current has developed along the lower southern slope in response to this cold layer and relatively cool air has started to pool at the bottom of the valley. This drainage current penetrates down to the valley bottom, is no more than $20 \mathrm{~m}$ deep and does not persist beyond this period. Such small localized drainage flows appear to be a common feature of the simulation, occurring on many other parts of the valley sides (see Figure 5). In the lower part of the valley (east of Duffryn), however, they do not appear to transport cold air down to the valley bottom consistently. This is consistent with recent observations of drainage flow and cold-pool development by Mahrt et al. (2010) and Bodine et al. (2009), but the role of advection in different parts of the valley will be examined in greater detail in section 5 .

Between 1800 and 1900 UTC, the appearance of relatively strong stable stratification in the valley has already prevented the northeasterly flow penetrating down to the bottom of the valley. The flow no longer sweeps through the valley and instead separates approximately halfway down the northern slope. The bottom of the valley is relatively sheltered. The cold pool continues to deepen and strengthen after 1900 UTC (see Figure 7(c) and (d)) and the stratification within the valley becomes progressively stronger. By 2100-2200 UTC (Figure 7(d)), the $\theta$ surfaces are almost horizontal in the cross-valley direction and the winds at the bottom of the valley are very light. The structure of the along- and down-valley flow that develops during the evening (observed in Figure 5(c)-(f)) is shown clearly as having a jet structure in Figure $7(\mathrm{~d})$, the maximum of which $\left(\sim 1.5 \mathrm{~m} \mathrm{~s}^{-1}\right)$ occurs approximately $30 \mathrm{~m}$ above the valley floor. This flow presumably forms in response to an along-valley pressure gradient, which arises due to the temperature contrast between the head and foot of the valley. A recent study by Schmidli and Rotunno (2010) has shown how various forcing mechanisms contribute to this pressure gradient. No further study of this particular phenomenon is undertaken here.

\subsection{Surface heat fluxes and temperature}

Maps of the hourly mean surface sensible heat flux and ground surface temperature perturbation, $T_{*}^{\prime}$, are shown in Figure 8 . Here $T_{*}^{\prime}=T_{*}-\bar{T}_{*}$, where $T_{*}$ is the surface temperature and the overbar denotes the spatial (across the domain) average. Note that $T_{*}^{\prime}$ is presented, rather than $T_{*}$ 
(a)

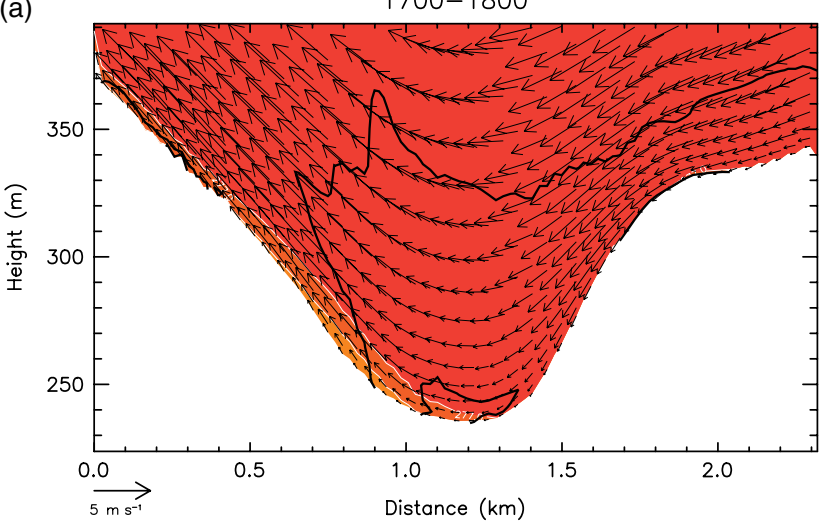

(c)
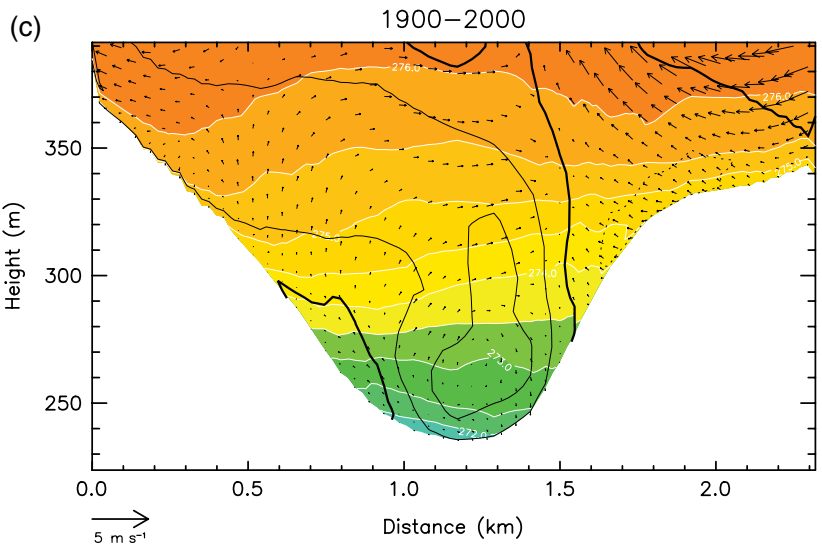

(b)

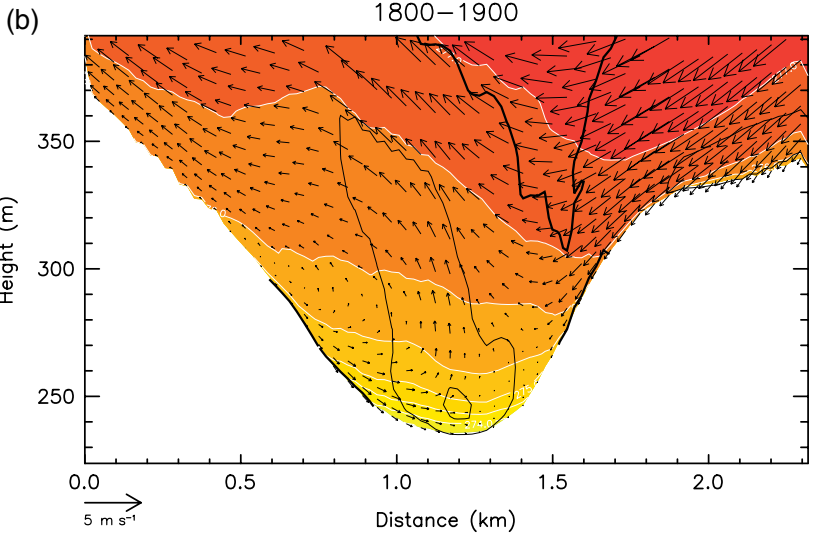

(d)

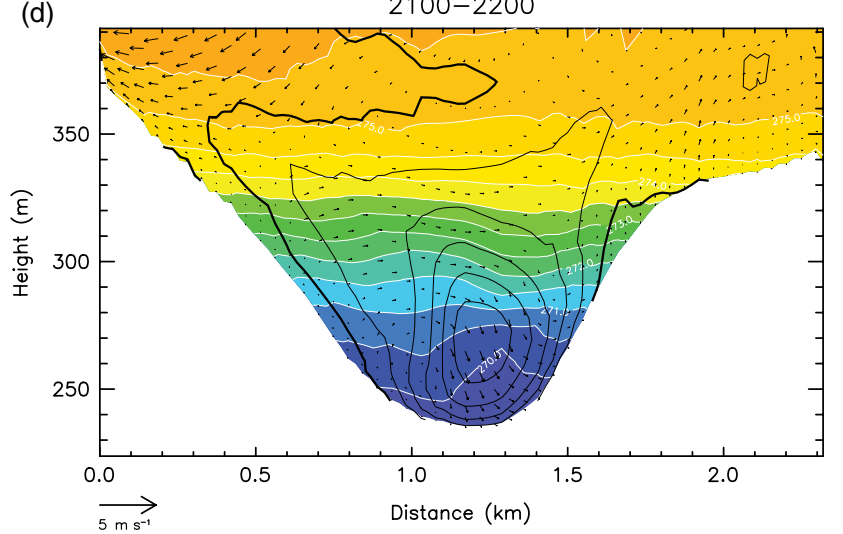

Figure 7. Vertical cross-sections across the valley showing hourly averaged $\theta$ (colour shading and white line contours, interval $0.5 \mathrm{~K}$ ), wind vectors projected on to the vertical plane and the component of the wind perpendicular to the plane (line contours, interval $0.25 \mathrm{~m} \mathrm{~s}^{-1}$ ). Solid line contours indicate positive values (out of the plane and down-valley). Dashed contours indicate negative values. The thick contour denotes zero values. The location of the cross-section is shown in Figure 5. The south side of the valley is to the left. Results are shown during IOP 16 for (a) $1700-1800$ UTC, (b) 1800-1900 UTC, (c) 1900-2000 UTC and (d) 2100-2200 UTC on 4 March 2010.

itself, simply because this allows a common shading scheme to be used in Figure 8. We also adopt the convention that a positive heat flux corresponds to upwards transport of heat, away from the ground. Between 1600 and 1700 UTC (Figure 8(a)), the mean heat-flux pattern contains both positive and negative values, with negative values mostly confined to north-facing slopes where the ground surface temperature is relatively low (Figure $8(\mathrm{~b})$ ). Note that the heat fluxes are relatively large and positive during the first part of the hour over the whole domain. Consistent with the stable stratification seen in Figure 6, by 1700 UTC the heat fluxes are predominantly negative but are small. The resulting hourly average fluxes are therefore skewed by the large positive values. Over the period 1800-1900 UTC (Figure $8(\mathrm{c})$ ), the mean surface heat flux is negative almost everywhere, with the strongest fluxes located across the exposed hillsides and summits. These relatively large downward heat fluxes will act to reduce the cooling of the ground surface and result in small $(\sim 1 \mathrm{~K})$ positive $T_{*}^{\prime}$ values across the hill summits (Figure $8(\mathrm{~d})$ ). Sheltering within the valley clearly reduces the surface heat flux and this results in a more rapid cooling of the ground within the valley (Figure 6) up to this point in time. However, whilst the air temperature in the valley is already lower than that outside by this time (Figure 5(a)), the higher surface temperatures in the late afternoon mean that the ground is still relatively warm over a large proportion of the valley bottom. The surface-temperature variations do not change dramatically between 1800-1900 and 2100-2200 UTC (Figure 8(f)). The ground is still warmer over the hill summits, although the higher temperatures on the south-facing slopes of the valley are somewhat reduced. The eastern portion of the floor of the Clun Valley still remains relatively warm. Figure 8(e) shows that although small $\left(\sim-10 \mathrm{~W} \mathrm{~m}^{-2}\right)$, a downward surface heat flux appears to be sustained in this part of the valley, which presumably suppresses the ground cooling. This heat flux is associated with the along-valley westerly drainage current, which has become established by this time (see Figure $7(d)$ ) and continues through the night. Note that patches of positive surface heat flux can be seen in the upper part of the Clun Valley, to the north west of Duffryn at this time. The near-surface air is cooler than the ground in these patches, presumably because the air has drained down to the valley floor from the (relatively cold) valley sides in this part of the valley. The significance of this transport of cold air for the overall cold-pool heat budget will be examined further in section 5 .

\section{The heat budget}

The various mechanisms that contribute to the formation of the simulated cold pools are now examined in the context of the model potential-temperature budget. The contributions to the local rate of change of $\theta$ in the model can be broken down as follows:

$$
\frac{\partial \theta}{\partial t}=\frac{\partial \theta}{\partial t}_{\mathrm{adv}}+\frac{\partial \theta}{\partial t}_{\text {mix }}+{\frac{\partial \theta}{\partial t_{\mathrm{rad}}}}+\frac{\partial \theta}{\partial t}_{\mathrm{cld}},
$$


(a)

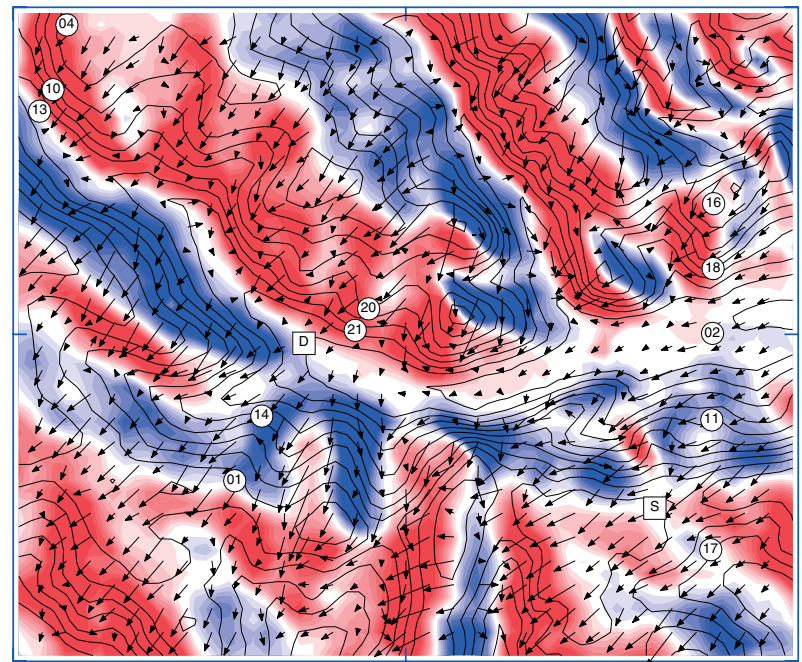

(c)

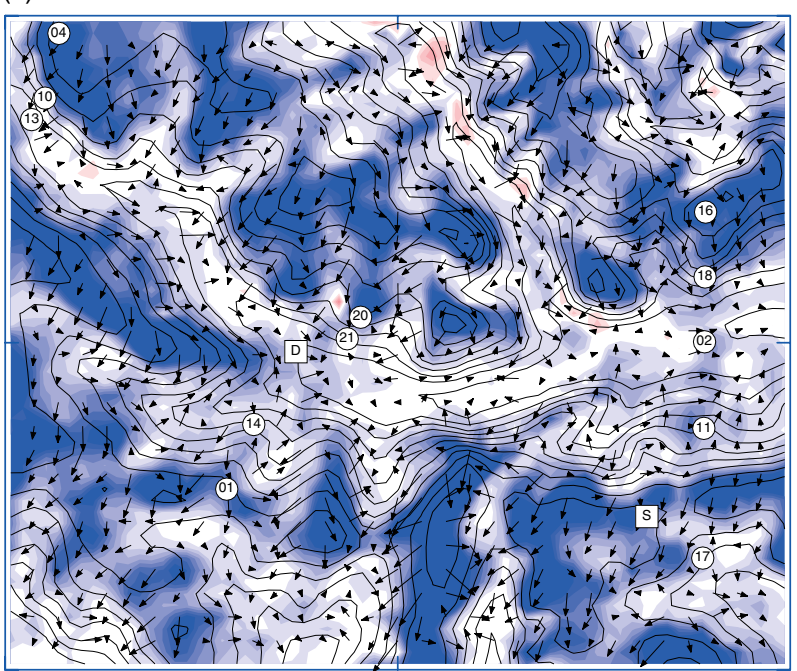

(e)

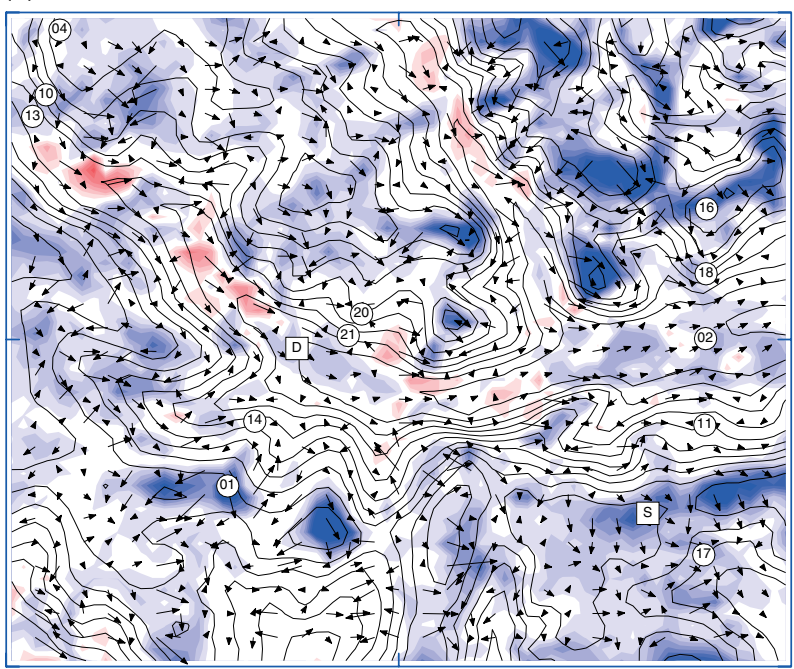

$\rightarrow 5$

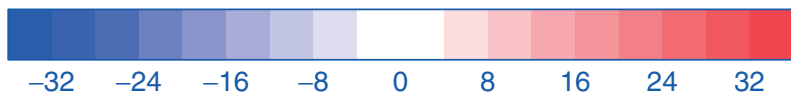

(b)

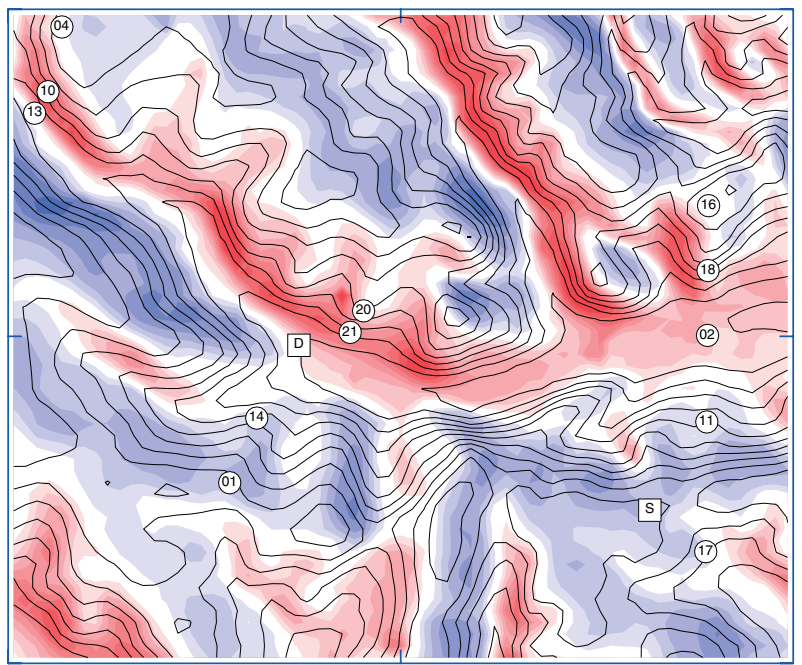

(d)

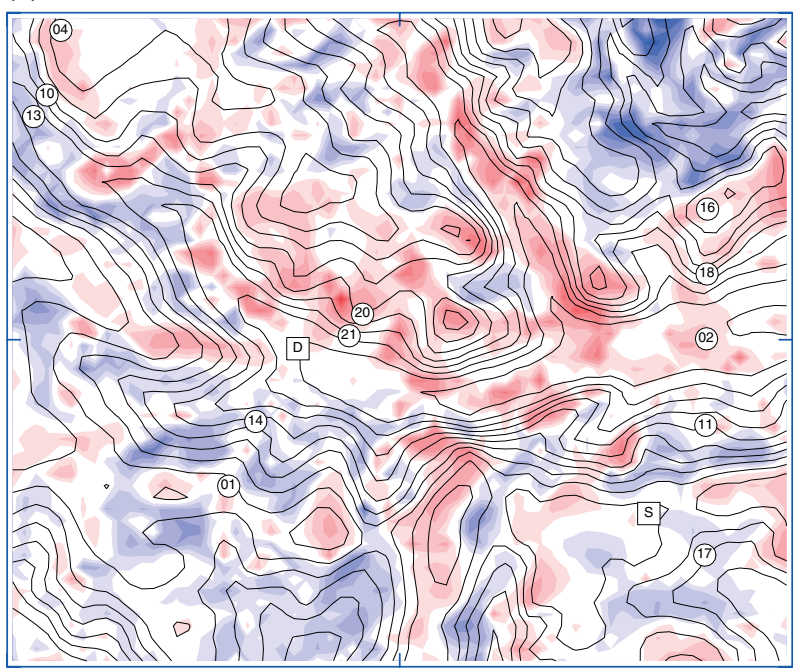

(f)
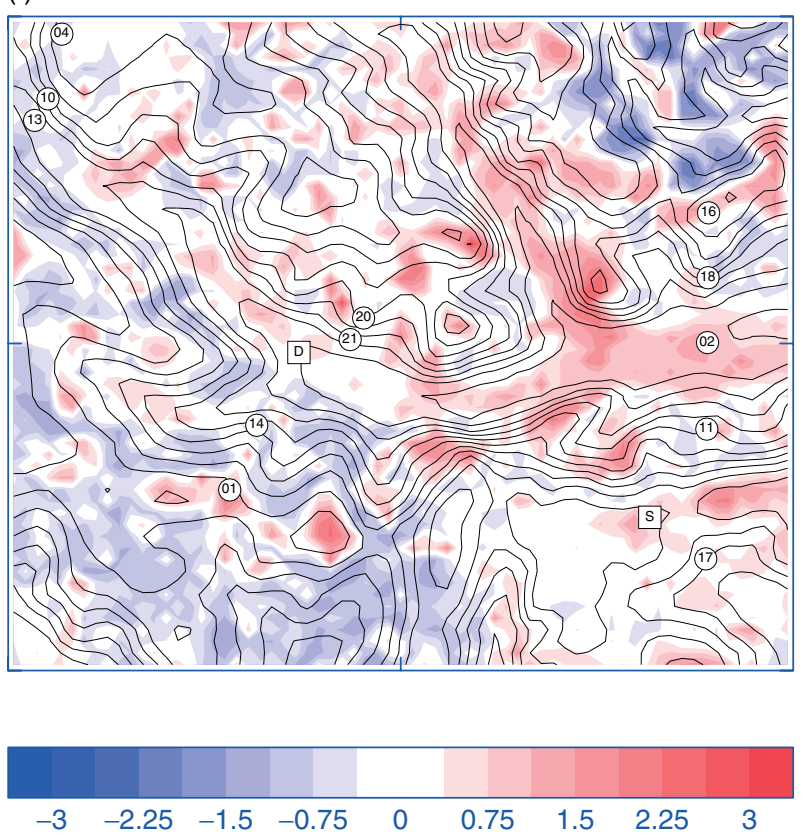

Figure 8. Simulated hourly mean surface quantities during IOP 16. Panels (a), (c) and (e) show the sensible heat flux (shaded, units $\mathrm{W} \mathrm{m} \mathrm{m}^{-2}$ ) over the periods 1600-1700 UTC, 1800-1900 UTC and 2100-2200 UTC, respectively. Panels (b), (d) and (f) show the perturbation surface temperature, $T_{*}^{\prime}$ (shaded, units K). Also shown in (a), (c) and (e) are the hourly mean $10 \mathrm{~m}$ wind vectors. Terrain height contours (interval, $20 \mathrm{~m}$ ) and the locations of the instrument sites are also shown. 
where $\partial \theta / \partial t_{\mathrm{adv}}$ is the contribution from advection, $\partial \theta / \partial t_{\text {mix }}$ is the contribution from parametrized turbulent mixing, $\partial \theta / \partial t_{\mathrm{rad}}$ is the radiative forcing and $\partial \theta / \partial t_{\mathrm{cld}}$ is the contribution from cloud microphysical processes. On the innermost grid, no other terms contribute to the $\theta$ budget. For IOP 16, $\partial \theta / \partial t_{\text {cld }}$ is negligible and the first three terms on the right-hand side of Eq. (1) dominate.

Since the turbulent mixing term, $\partial \theta / \partial t_{\text {mix }}$, is parametrized by a 3D Smagorinsky-Lilly scheme (see section 3), it should include a contribution from both horizontal and vertical mixing. However, the contribution from horizontal diffusion is found to be much smaller (by at least two orders of magnitude) than that from the vertical mixing. This is consistent with sensitivity tests (not shown), which show little impact of replacing the 3D mixing with the standard 1D boundary-layer scheme (Lock et al., 2000). To a very good approximation, therefore, $\partial \theta / \partial t_{\text {mix }}$ is determined by the vertical gradient of the parametrized vertical flux, $H_{z} /\left(\rho c_{\mathrm{p}}\right)$, where $H_{z}$ is the vertical turbulent heat flux, $\rho$ is the density and $c_{\mathrm{p}}$ is the specific heat capacity. For convenience, the small horizontal mixing contribution has been omitted from $\partial \theta / \partial t_{\text {mix }}$ in the subsequent analysis.

\subsection{Site-specific analysis}

Time series of the cumulative contributions from $\partial \theta / \partial t_{\mathrm{adv}}$, $\partial \theta / \partial t_{\text {mix }}$ and $\partial \theta / \partial t_{\text {rad }}$ during IOP 16 are shown in Figure 9 for Duffryn and Springhill. The results are presented as accumulated contributions to the change in potential temperature $(\Delta \theta)$ at $2 \mathrm{~m}$ relative to the mean value between 1600 and 1700 UTC. The time series have been averaged hourly but were obtained using the model data output at each (5s) time step. Figure 9(a) shows that, at Springhill, the budget is dominated by contributions from advection and turbulent mixing. These terms (divided by a factor of 10 before plotting) far exceed the contribution from radiative cooling. Advection provides a warming effect and, to a good approximation, this is balanced by a cooling effect from turbulent mixing. Relatively warm air is transported across the surface at Springhill and the turbulent heat-flux divergence (between the surface and $3.67 \mathrm{~m}$ ) acts to cool this air. These two terms are in approximate balance and the overall net cooling is largely provided by radiative cooling. Note that the sum of the advective, turbulent mixing and radiative terms very closely approximates the overall cooling, confirming that other processes have a negligible effect.

The roles of advection and turbulent mixing at Duffryn are similar to those at Springhill. Figure 9(b) shows that advection again provides a warming tendency, although as expected this is smaller than at the more exposed Springhill site (the advection and turbulent mixing terms are divided by a factor of 4 in this case). However, at Duffryn the cooling from turbulent mixing outweighs the warm advection, providing an overall cooling. The sum of these two terms accounts for a large proportion of the net cooling rate. Beyond 2000 UTC, radiative cooling plays a less important role than at Springhill. This is to be expected given that the air temperature approaches the ground temperature within the valley (see Figure 6).

The above analysis suggests that it is the balance of contributions from advection and the turbulent heatflux divergence that promotes the development of colder near-surface air temperatures at Duffryn, compared with Springhill. Despite the fact that the surface heat flux is smaller
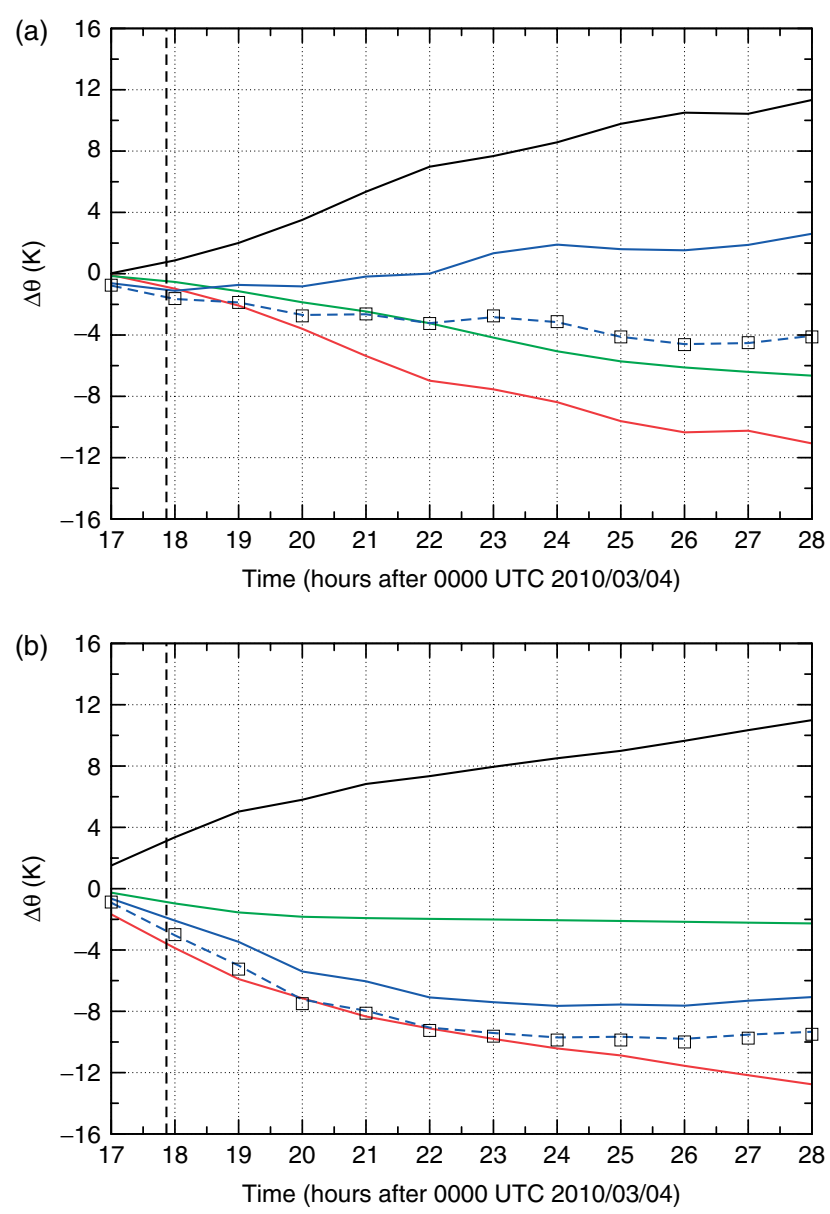

Figure 9. Time series of the model hourly mean cumulative contributions to the change in the $2 \mathrm{~m}$ potential temperature, $\Delta \theta$, at (a) Springhill and (b) Duffryn during IOP 16. The quantities shown are the contributions to $\Delta \theta$ from advection (solid black), parametrized turbulent mixing (red), radiative cooling (green), the sum of the advection and parametrized turbulent mixing contributions (solid blue), the sum of advection, parametrized turbulent mixing and radiative contributions (dashed blue) and the change in potential temperature, $\Delta \theta$, itself (squares). $\Delta \theta$ is relative to the average value of $\theta$ between 1600 and 1700 UTC. All other quantities are the cumulative contributions since 1700 UTC. The vertical dashed black line denotes the local sunset time at Springhill. Note that the contributions from advection and turbulent mixing are divided by factors of (a) 10 and (b) 4 , however the sums of these terms (solid blue and dashed blue lines) have not been rescaled.

at Duffryn than at Springhill, the near-surface vertical gradient is relatively large compared with the advection term. This provides a higher net cooling rate. This is consistent with the idea that local sheltering (i.e. the rapid decay of turbulence with height) is largely responsible for the coldpool formation. Of course, in the limiting case of complete sheltering, in which no turbulent mixing occurs at all, the turbulent heat-flux divergence would make no contribution to the temperature budget. At Duffryn, on the other hand, local drainage flows at the valley bottom sustain small levels of turbulence close to the surface.

\subsection{Valley-scale analysis}

The extent to which the above conclusions hold across the valley as a whole, rather than at specific sites, can be determined by examining the spatial variability in the contributions to $\partial \theta / \partial t$. Figure 10 shows hourly mean $\partial \theta / \partial t_{\mathrm{adv}}, \partial \theta / \partial t_{\text {mix }}$, the sum of these two terms and the total $\partial \theta / \partial t$ at $2 \mathrm{~m}$, between 1800 and 1900 UTC. Outside 
(a)
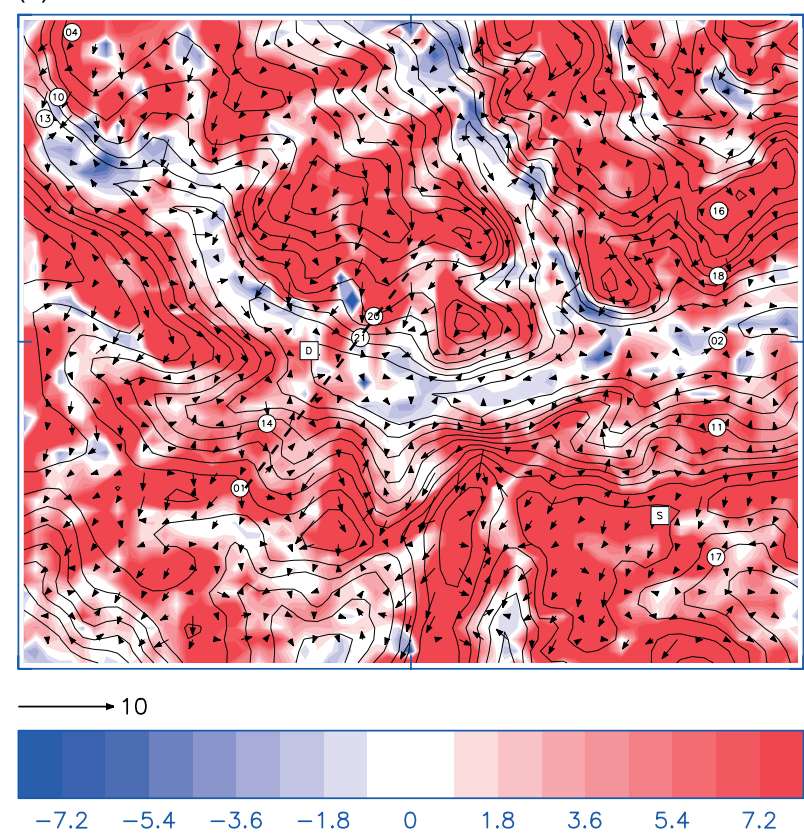

(c)
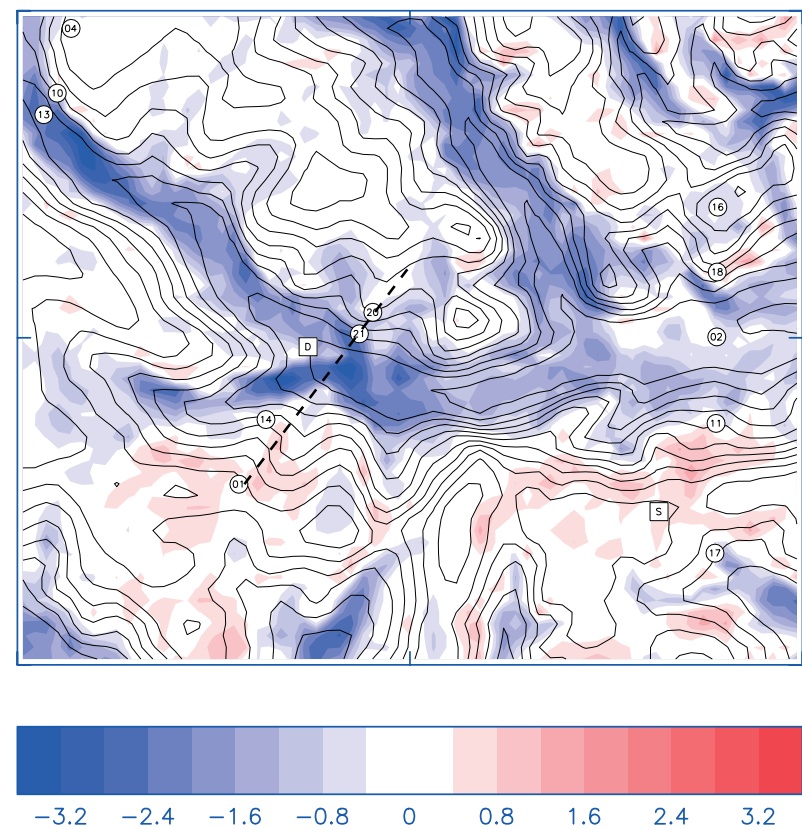

(b)
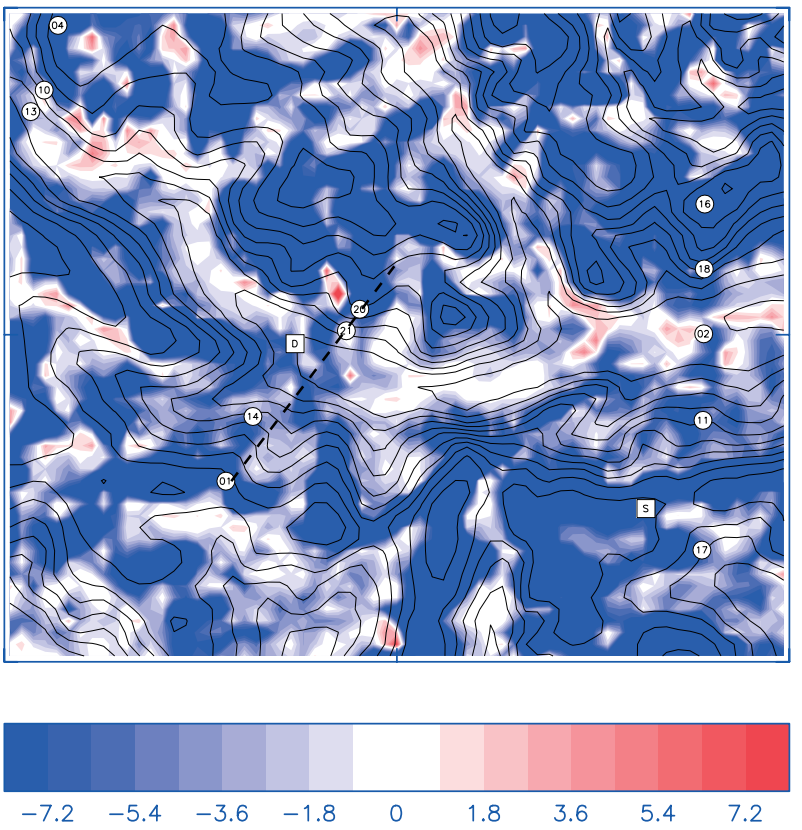

(d)
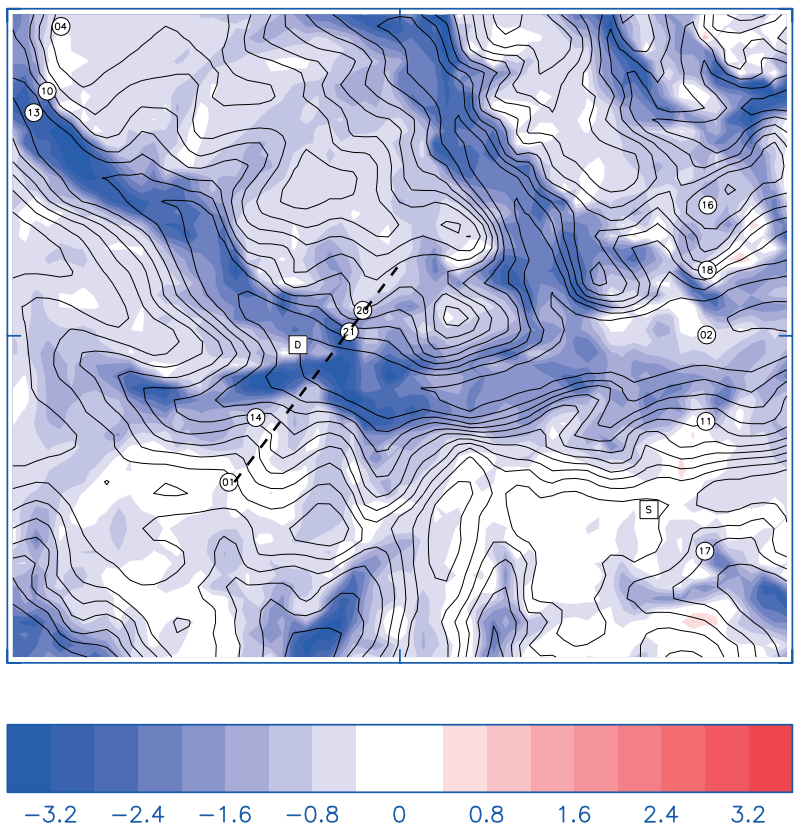

Figure 10. Hourly mean contributions to the $2 \mathrm{~m} \theta$ budget during IOP 16 between 1800 and 1900 UTC. The quantities shown are the contributions to $\partial \theta / \partial t$ from (a) advection, (b) parametrized turbulent mixing, (c) the sum of the advection and turbulent mixing terms and (d) the total $\partial \theta / \partial t$. The units shown are $\mathrm{Kh}^{-1}$. Also shown are terrain height contours (interval $20 \mathrm{~m}$ ) and the locations of the instrument sites. In (a), the hourly averaged wind vectors on the lowest level are also shown. The dashed line marks the orientation of the vertical cross-section presented in Figure 13.

the valley it is clear that $\partial \theta / \partial t_{\mathrm{adv}}$ (Figure $10(\mathrm{a})$ ) is generally positive, consistent with the behaviour seen at Springhill. In the valley, however, the sign is more variable: both positive and negative values exist. The strongest patches of cold advection are present on the floor of the upper part of the valley (northwest of Duffryn) as well as on the valley sides, particularly in the tributary that extends northnorthwest of the Clun Valley. Comparison with Figure 8(c) shows that many of these cold advection patches correspond to positive surface heat flux. The temperature of the air arriving at these locations is lower than that of the ground surface, which is still relatively warm as a result of local heating differences around sunset.
The $\partial \theta / \partial t_{\text {mix }}$ term (Figure $10(\mathrm{~b})$ ) is dominated by negative values outside the valley, again consistent with the signal at Springhill. As expected, and consistent with the surface heat fluxes (Figure 8(c)), smaller negative values are present within the valley, which is relatively sheltered and hence less turbulent. Some localized positive values of $\partial \theta / \partial t_{\text {mix }}$ do exist within the valley, however. Again, the locations of these correspond to the warmer ground surface temperatures and positive surface heat fluxes (Figure 8(c) and (d), respectively) and are collocated with the patches of cold advection discussed above.

The sum of the advective and turbulent mixing tendencies is shown in Figure 10(c). It is clear that within the valley 


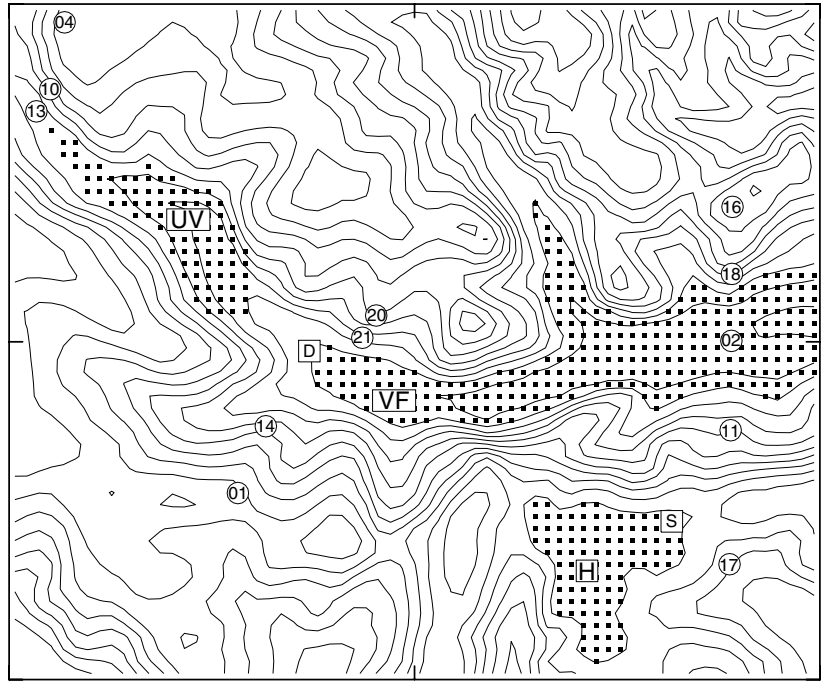

Figure 11. The three averaging regions used to examine the behaviour of the potential-temperature budget in and outside the valley. The regions are labelled 'VF' (lower valley floor), 'UV' (upper valley floor) and ' $H$ ' (hill-top). The grid points within each region are marked with squares. Terrain height contours (interval $20 \mathrm{~m}$ ) and the locations of the instrument sites are shown.

this is a good approximation to the total $\theta$ tendency shown in Figure 10(d). Across the hills, however, these terms approximately cancel and the radiative cooling term (not shown) provides the missing overall cooling. This is again consistent with the previous site-specific analysis for Springhill and Duffryn.

Since the behaviour of the cold pool as a whole is of more interest than that at any specific location, it is useful to examine volume-averaged quantities. Three distinct regions have been specified. The sets of grid points forming these are illustrated in Figure 11 and are labelled as VF, UV and $\mathrm{H}$. They were chosen to cover the lower valley floor (region VF), the upper portion of the valley floor (region UV) and a hill-top region (region $\mathrm{H}$ ). Regions $\mathrm{VF}$ and $\mathrm{H}$ include the Duffryn and Springhill sites, respectively. The contributions to $\partial \theta / \partial t$ have been spatially averaged within these regions. Hourly averaged profiles of all terms in Eq. (1), other than $\partial \theta / \partial t_{\text {cld }}$, are shown in Figure 12 for the VF region. Profiles are presented between 1600 and 2200 UTC. The profiles were computed by averaging data along the model (terrainfollowing) levels and are plotted against the mean height above ground level.

Figure 12(a) shows that after 1700 UTC the average surface heat flux on the lower valley floor (VF region) is small and negative $\left(\sim-5 \mathrm{~W} \mathrm{~m}^{-2}\right)$. Whilst the flux itself is small, the decay of turbulence away from the surface implies a vertical flux gradient, which results in a mean value of $\partial \theta / \partial t_{\text {mix }}$ at $2 \mathrm{~m}$ of approximately $-2 \mathrm{~K} \mathrm{~h}^{-1}$ between 1600 and $1900 \mathrm{UTC}$ at $2 \mathrm{~m}$, reducing to $-1 \mathrm{Kh}^{-1}$ after 1900 UTC (Figure 12(c)). Also shown in Figure 12(a) are the measurements of the vertical turbulent heat flux made on the Duffryn flux tower. The fluxes were measured using an averaging period of $10 \mathrm{~min}$ and mean flux values are shown at $2.5,10$ and $25 \mathrm{~m}$ for the period 1700 and 2200 UTC. The measurements are of a similar magnitude to the model results and are roughly independent of height, consistent with the model profiles for the VF region above the lowest few metres.

Whilst Figure 9(b) showed that advection contributed a warming tendency at Duffryn, when a larger region of the lower valley is considered its mean contribution near the valley floor is small. The detailed structure in $\partial \theta / \partial t_{\text {adv }}$ seen in Figure 10(a), reflecting localized temperature variations and flows along the valley floor, averages to only a small value at $2 \mathrm{~m}$ (Figure 12(b)). Although initially (between 1600 and 1900 UTC) advection provides a warming tendency at $2 \mathrm{~m}$, this reduces with time and becomes negligible later on. As shown by Figure 12(d), radiative cooling plays a relatively minor role in the valley and exhibits the expected decay in time as the air temperature approaches that of the ground.

It is clear that when a large area of the lower part of the valley is considered, rather than a single point, the most important process in the $2 \mathrm{~m} \theta$ budget is the turbulent heatflux divergence. The reduction in the downward turbulent heat flux over the lowest few metres allows the near-surface air to cool rapidly. Above this (above $\sim 5 \mathrm{~m}$ ) the turbulent flux is small and rather uniform with height, meaning that $\partial \theta / \partial t_{\text {mix }}$ does not contribute to the cooling (Figure 12(c)). Instead the cooling is largely a result of cold advection, along with a small contribution from radiative cooling. The sign of $\partial \theta / \partial t_{\text {adv }}$ is consistently negative above $5 \mathrm{~m}$ after 1700 UTC.

A more detailed view of the important contributions to the $\theta$ budget in the lower part of the valley is provided by Figure 13, which shows $\partial \theta / \partial t_{\mathrm{adv}}$ and $\partial \theta / \partial t_{\text {mix }}$ along the vertical cross-valley section (see Figure 10). Hourly mean results are shown for the periods 1800-1900 UTC and 2000-2100 UTC. Figure 13(a) shows that during the earlier of these periods the heat-flux divergence cools the air in thin layers adjacent to the ground, both at the bottom of the valley and also across the hill to the north (upstream). The flow separation from the valley side causes this cold air to be advected away from the surface into the interior of the flow (Figure 13(b)). At the same time, the thin drainage flow along the southern slope (see section 4.2) collides with the cold pool at the bottom of the valley. This causes upward motion and vertical advection of the cold-pool air into the interior atmosphere of the valley. By 2000-2100 UTC, the atmosphere is strongly stably stratified throughout the depth of the valley. The penetration of the exterior flow down the northern valley side, and subsequent separation, no longer occurs. Figure 13(d) shows that advection provides a cooling tendency above the valley floor and this is largest in the region of the down-valley drainage flow. It is not associated with transport away from the valley floor or sides along this particular cross-section but is a consequence of advection of cold air from further up the valley. Note that idealized simulations of cooling inside a basin conducted by Kiefer and Zhong (2011) also suggest that advection can play an important role in cooling the air above the bottom of the basin. Very close to the surface, the cooling of the air was dominated by the heat-flux divergence but cold advection dominated the cooling above. In Kiefer and Zhong's study this occurred as a result of a regional-scale cold drainage flow that spilled into the basin, both replacing relatively warm air in the interior of the basin and causing broad upward motion (consistent with mass conservation) of the cold pool.

The heat flux and $\theta$ tendency profiles for the upper-valley (UV) region are shown in Figure 14. The cooling of the air at $2 \mathrm{~m}$ is again dominated by the turbulent heat-flux divergence, which is larger than in the VF region because of the greater magnitude of the turbulent heat flux in this part of the valley. As for the VF region, between 1600 and 1900 UTC advection contributes a warming at $2 \mathrm{~m}$ and this 
(a)

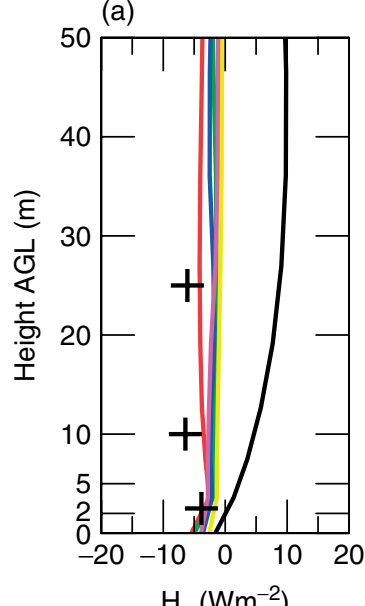

(b)

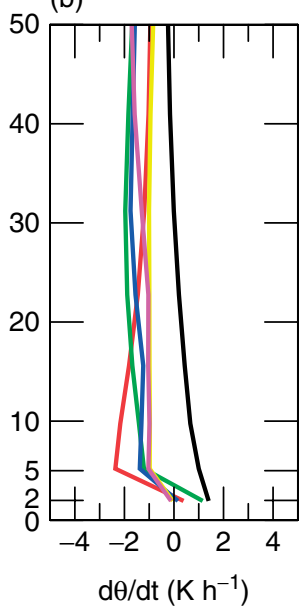

(c)

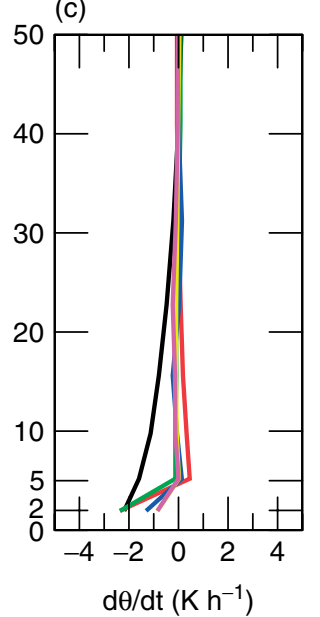

(d)

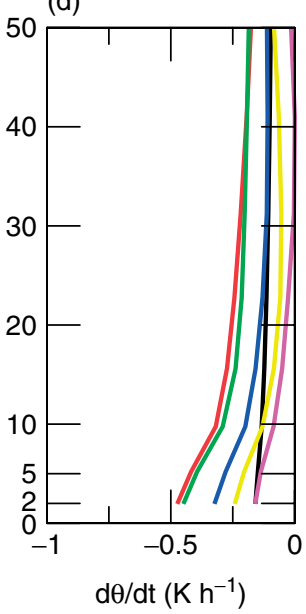

(e)

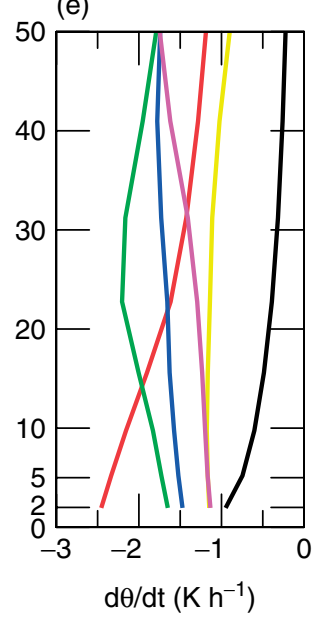

Figure 12. Model profiles of (a) turbulent heat flux and (b)-(e) contributions to $\partial \theta / \partial t$ during IOP 16. The contributions shown are those from (b) advection, (c) turbulent mixing, (d) radiative cooling and (e) the total from these three terms. The heat flux and tendency profiles are spatially averaged across the valley-floor region (VF) shown in Figure 11. Hourly mean profiles of the spatially averaged quantities are shown at $1 \mathrm{~h}$ intervals: 1600-1700 UTC (black), 1700-1800 UTC (red), 1800-1900 UTC (green), 1900-2000 UTC (blue), 2000-2100 UTC (yellow) and 2100-2200 UTC (magenta). Also shown (' + ') are the measured mean vertical turbulent heat fluxes over the 1700-2200 UTC period at Duffryn. Measurements were made at heights of $2.5,10$ and $25 \mathrm{~m}$.
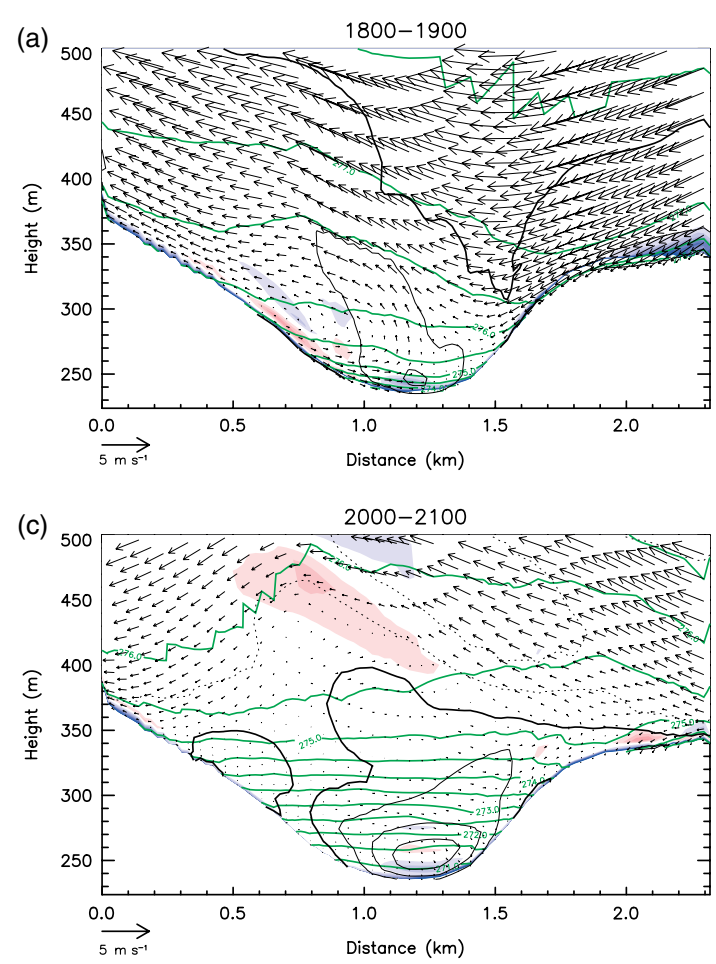
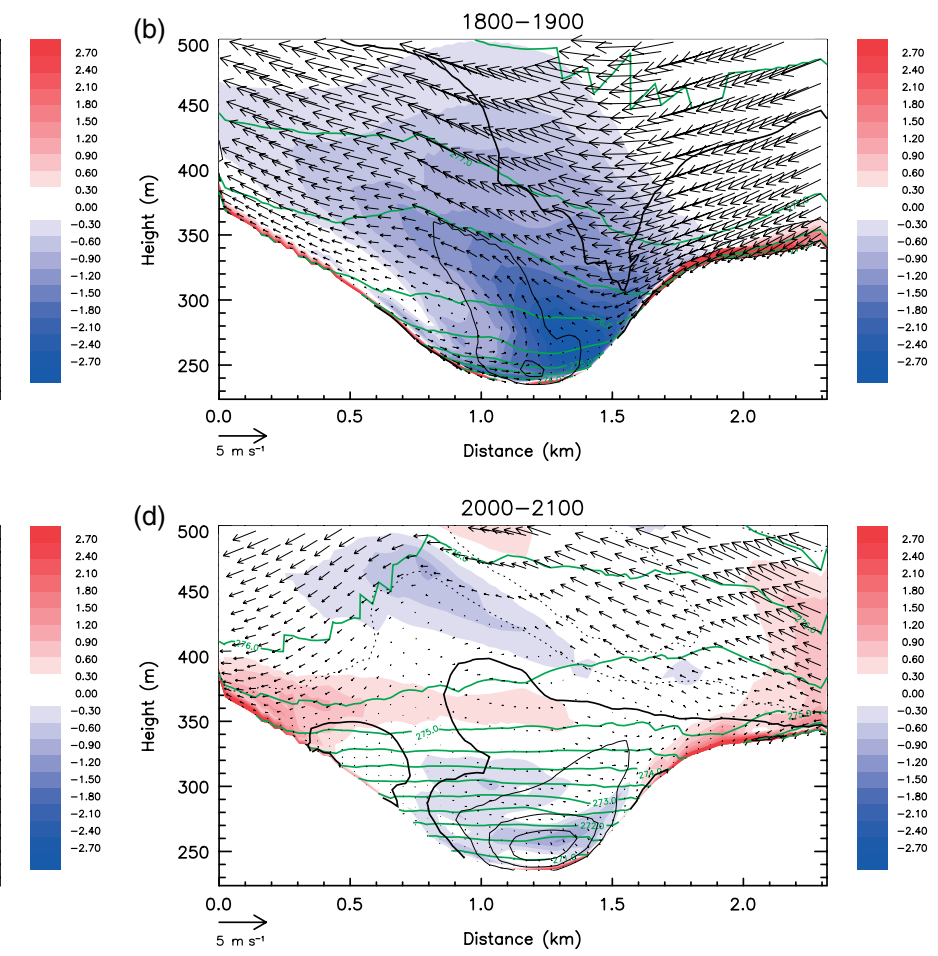

Figure 13. Vertical cross-sections across the valley showing hourly averaged flow fields and contributions to $\partial \theta / \partial t$ for the IOP 16 simulation. Green contours denote potential temperature (interval $0.5 \mathrm{~K}$ ). Arrows denote wind vectors projected on to the vertical plane and the component of the wind perpendicular to the plane is shown by black contours with solid lines indicating positive values (out of the plane and down-valley) and dashed contours indicating negative values (interval $0.25 \mathrm{~m} \mathrm{~s}^{-1}$ ). The thick contours denote zero values. The colour shading in panels (a) and (c) shows hourly averaged $\partial \theta / \partial t_{\text {mix }}$. Panels (b) and (d) show $\partial \theta / \partial t_{\text {adv }}$ (units $\mathrm{Kh}^{-1}$ ). Results for 1800-1900 UTC are shown in (a) and (b). Panels (c) and (d) show results for 2000-2100 UTC. The location of the cross-section is shown in Figures 5 and 10. The south side of the valley is to the left.

reduces in time. After 1900 UTC, however, the advection consistently acts to cool the $2 \mathrm{~m}$ air in the upper valley. This is presumably a result of drainage of cold air from the valley sides down to the valley floor, an effect that might be enhanced by the development of the along-valley westerly drainage flow, which for mass continuity reasons must draw air down into the valley. The fact that cold advection below $5 \mathrm{~m}$ occurs in the upper part of the valley (UV) but not in the lower part of the valley (VF) is presumably a result of the lower near-surface temperatures further down-valley and greater buoyancy forces, which prevent the drainage penetrating down to the bottom of the cold pool. The dominance of cold advection above $5 \mathrm{~m}$ in the VF region is consistent with the along-valley drainage flow surmounting the cold pool.

The contrast between the $\theta$ budget inside the valley and that outside is illustrated by the profiles averaged across the hill-top region $\mathrm{H}$, shown in Figure 15. As expected, given the greater exposure, the turbulent heat fluxes are considerably larger than in the valley, varying between 
(a)

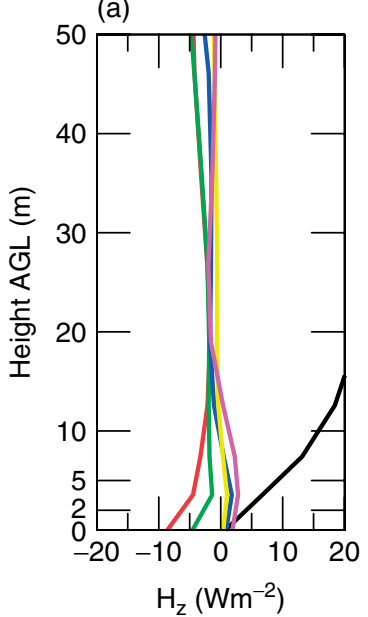

(b)

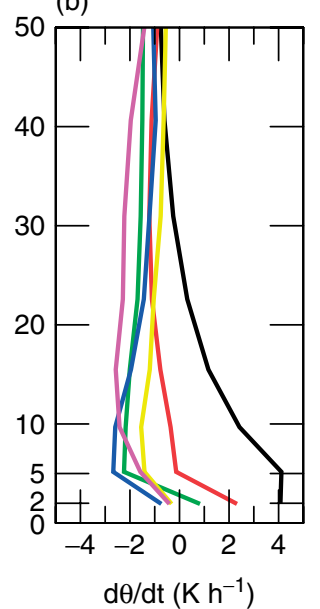

(c)

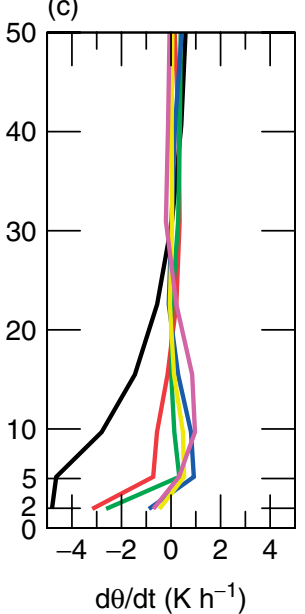

(d)

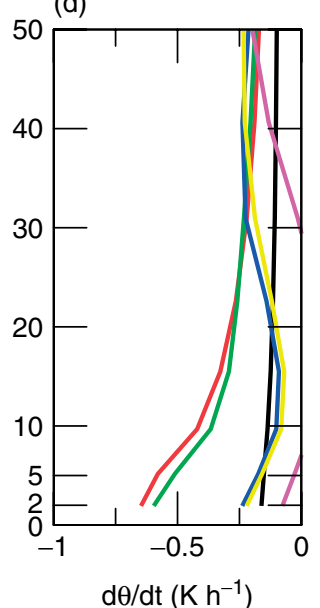

(e)

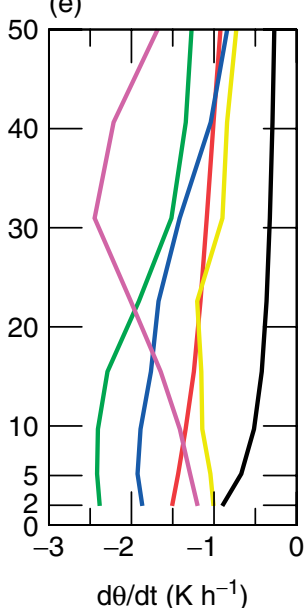

Figure 14. As for Figure 12, but for the region covering the upper part of the valley (UV) shown in Figure 11.

(a)

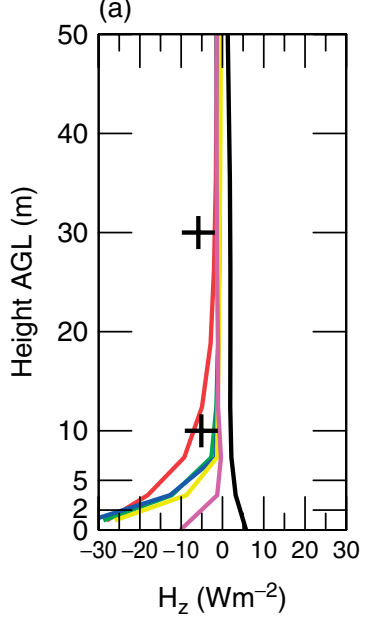

(b)

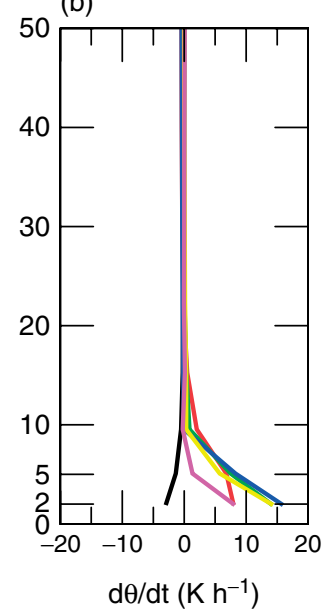

(c)

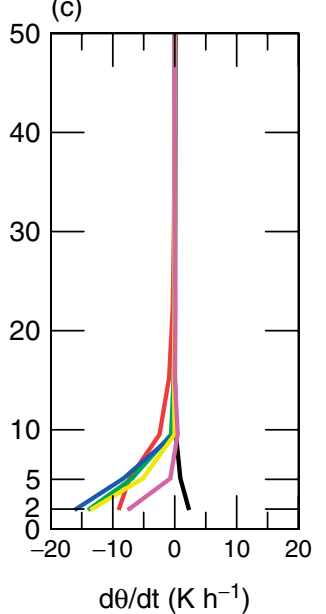

(d)

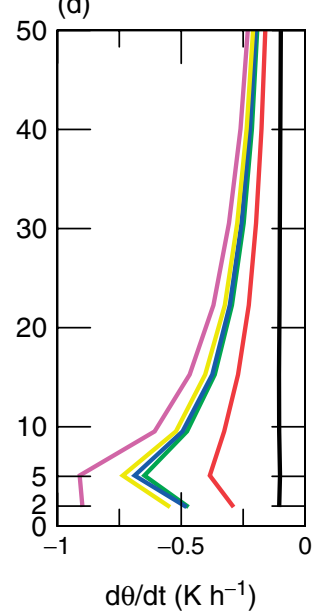

(e)

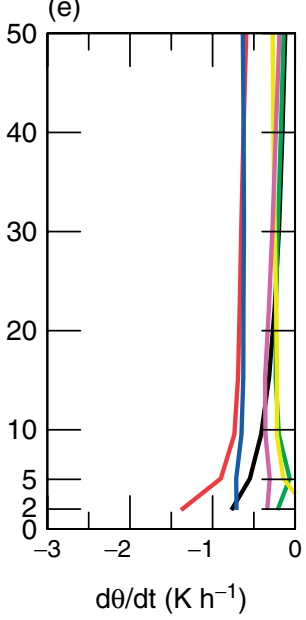

Figure 15. As for Figure 12 but for the region covering the hill (H) shown in Figure 11. Also shown (' + ') are the measured mean vertical turbulent heat fluxes over the 1700-2200 UTC period at Springhill. Measurements were made at heights of 10 and $30 \mathrm{~m}$.

approximately -30 and $-10 \mathrm{~W} \mathrm{~m}^{-2}$ between 1700 and 2100 UTC at the surface. Also shown in Figure 15(a) are the measured heat fluxes at 10 and $30 \mathrm{~m}$ at Springhill, averaged over the period 1700-2200 UTC. The fluxes are similar in size to the simulated values in the hill-top region and, as in the model, they are approximately constant over this height range. The decay of the model turbulence with height below $10 \mathrm{~m}$ implies large negative values of $\partial \theta / \partial t_{\text {mix }}$ but, as with the site-specific budget at Springhill, the area-averaged tendency is approximately balanced by advective warming. A relatively large proportion of the mean net cooling comes from radiative cooling.

The above analysis of the heat budget across the valley as a whole, rather than at single points, again supports the idea that the cold pools develop largely in response to a sheltering effect. On average, the cooling close to the surface is controlled by the vertical turbulent heat-flux divergence, which, despite the lower levels of turbulence in the valley, is large relative to the other terms. Advection plays a minor role very close to the ground in the lower part of the valley, but has a cooling effect above $5 \mathrm{~m}$. This cold advection is associated with transport of cold air away from the surface, from the valley sides or from further up the valley.

Note that the extent to which the above results hold more generally has been tested by repeating the analysis for a simulation of another clear-sky cold-pool case, IOP 4, which was observed during 9-11 September 2009. The level of agreement between the model and observed winds and temperatures is similar to that obtained with IOP 16. The model provides a realistic description of the cold pool. The results of the $\theta$ budget analysis are similar to those shown here. Again, $\partial \theta / \partial t_{\text {cld }}$ is negligible and the budget was dominated by contributions from $\partial \theta / \partial t_{\text {mix }}, \partial \theta / \partial t_{\text {adv }}$ and $\partial \theta / \partial t_{\text {rad }}$. As with IOP 16, an along-valley westerly flow developed during the evening, resulting in advective cooling in the upper part of the valley near the ground. This flow did not penetrate down to the ground in the lower part of the valley, where the turbulent heat-flux divergence term dominated the cooling. Across the hill-top region, the considerably larger heat-flux divergence is in approximate balance with advective warming and radiative cooling accounts for a large proportion (approximately two thirds) of the overall cooling of the $2 \mathrm{~m}$ air.

\section{Summary and conclusions}

The numerical simulations performed in this study provide a realistic description of the cold pools that develop in the Clun Valley during clear, calm nights. The model provides accurate predictions for the differences in screen 


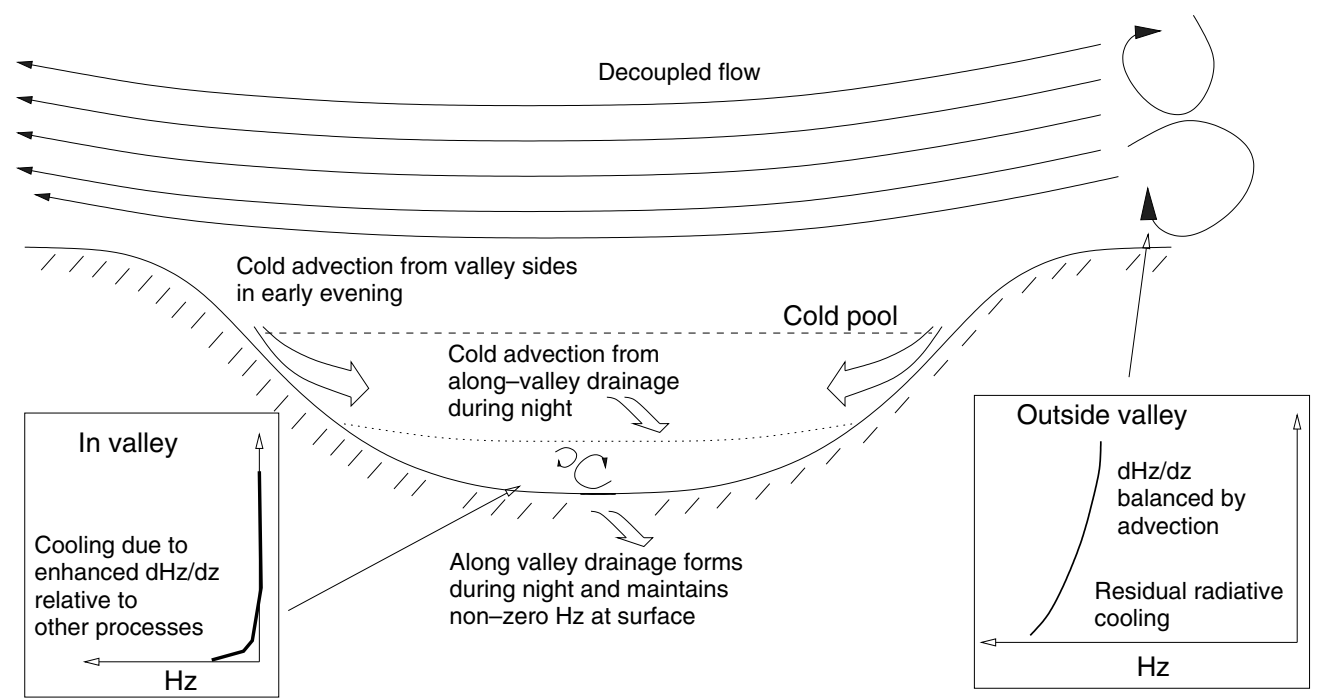

Figure 16. A schematic diagram illustrating the key processes involved in the more rapid decrease of air temperature within the valley, relative to that outside the valley.

temperature between the hill-top and valley bottom, as well as for the flow within the valley. Whilst these aspects are well represented by the model, there are some areas where the simulations are in need of improvement. For example, the simulated cold pool is too broad in the narrow parts of the valley. Whilst the reasons for this have not been investigated, it seems likely that further enhancements in horizontal resolution will affect the model cold-pool structure. Even at $100 \mathrm{~m}$ resolution, the narrower parts of the Clun Valley are not particularly well resolved. The solutions may also be affected by further enhancements to vertical resolution. In particular, the height above which the parametrized turbulence decays to zero in stable conditions is likely to be sensitive to the grid. This may have implications for the model heat budget, although it seems unlikely it would significantly affect the main conclusions of the study. In terms of the sensitivity of model results to resolution, it is also worth noting that, even with a grid spacing of $100 \mathrm{~m}$, the resolved turbulent heat fluxes were found to be negligible at Duffryn during stable night-time conditions. However calculations of the resolved near-surface heat flux during the early afternoon (not shown) suggest that it amounts to approximately $20 \%$ of the parametrized flux during unstable conditions.

An analysis of the model potential-temperature budget over the lower and upper parts of the valley suggests that a sheltering mechanism is responsible for the formation of the cold pools. This is in agreement with the results of Vosper and Brown's (2008) simple numerical simulations and also the deductions made from previous field studies (Bodine et al., 2009). In the model, the sheltering provided by the valley causes a turbulent heat-flux divergence over the lowest $5 \mathrm{~m}$ above the valley floor that is large compared with the other terms in the $\theta$ budget. This causes relatively rapid cooling of the air adjacent to the ground. Note that in the limit of complete sheltering, in which the surface sensible heat flux is zero, the land surface would decouple from the atmosphere and the turbulent heat-flux divergence between the near-surface and the ground would not result in cooling. This does not occur in the situation considered here, because local flows (e.g. along-valley drainage) help to maintain small levels of turbulent mixing. The limit in which the turbulence vanishes completely, other than perhaps in a very localized sense, is likely to be a hypothetical one.

Across the surrounding hills, the turbulent heat-flux divergence is actually larger than that in the valley because of the greater exposure (and thus higher levels of turbulence). However the enhanced cooling tendency this provides is approximately balanced by an almost equally larger warming tendency from advection. The net effect of these two terms is small compared with that in the valley and thus the cooling rate is smaller.

The simulations show that the contribution to the $\theta$ budget close to the ground (at $2 \mathrm{~m}$ ) from advection appears to be highly variable across the valley floor. Regions of both cooling and warming exist. This local variability suggests two things. Firstly, in order to draw conclusions about the processes controlling the cold pool it is important to analyze the budget over large representative volumes, rather than at single points. Secondly, the interpretation of field measurements is likely to be difficult. In particular, closing the $\theta$ budget using measurements from a sparse network of instruments will in general be very challenging.

In the model simulations, the parametrized turbulence decays rapidly above the valley floor soon after the cold pools begin to form (by sunset). Above $5 \mathrm{~m}$, the contribution to the $\theta$ budget from the turbulent heat-flux divergence is very small and advection dominates the cooling process. This cold advection is associated with transport away from the valley sides and floor into the interior of the valley atmosphere. In the case considered here, this transport is associated with separation of a weak cross-valley flow from the valley sides in the early evening. Later on, once the cold pool has become established and the cross-valley flow no longer descends down the valley sides, the cold advection is primarily due to an along-valley drainage current. A schematic diagram illustrating these key processes is presented in Figure 16.

Although not explored in this study, it is interesting to note that the separation of the cross-valley flow during the early evening is likely to be influenced by the increase in stability along the valley bottom as the cold pool forms. This suggests that a positive feedback mechanism may exist, in which the growth of the cold pool will further enhance the sheltering and lead to more rapid cooling in the valley. 
The results from this study potentially have important implications for the development of post-processing techniques designed to account for the effect of subgrid terrain on NWP and climate-model temperature predictions (Sheridan et al., 2010). The importance of the sheltering effect suggests that a parametrization to account for reduced downward turbulent heat flux in subgrid valleys could be used to improve temperature predictions in complex terrain. Note, however, that this study has been limited to a small, relatively narrow $(\sim 1 \mathrm{~km})$ valley with steep sides. It is not clear to what extent the results would be applicable to valleys or basins with a different geometry. For example, it is likely that the centre of a sufficiently wide valley will be no more sheltered than the surrounding hills. The reduction in turbulence may be limited to the valley sides only and the cold pools that develop may have different properties from those studied here. The relative importance of drainage into such wide valleys or basins (e.g. via tributary valleys) is also likely to differ. Clearly, further work is required to understand more generally how the valley geometry and flow properties will dictate the relative importance of the different processes controlling the formation of cold pools.

\section{Acknowledgements}

The efforts of all those involved in the COLPEX field campaign are very much appreciated. The authors also thank Peter Clark, Emilie Carter, Stuart Webster and Humphrey Lean for their help with setting up and testing the model. This study has benefited from helpful conversations with John Edwards, Jeremy Price, Volker Horlacher, Aurore Porson and Roy Kershaw. The comments of two anonymous reviewers have also improved this manuscript. John Hughes' contribution was funded by the UK Natural Environment Research Council and UK Met Office through the Joint Weather and Climate Research Programme under grant $\mathrm{NE} / \mathrm{I} 007679 / 1$.

\section{References}

Barr S, Orgill MM. 1989. Influence of external meteorology on nocturnal valley drainage winds. J. Appl. Meteorol. 28: 497-517.

Best MJ, Pryor M, Clark DB, Rooney GG, Essery RLH, Ménard CB, Edwards JM, Hendry MA, Porson A, Gedney N, Mercado LM, Sitch S, Blyth E, Boucher O, Cox PM, Grimmond CSV, Harding RJ. 2011. The Joint UK Land Environment Simulator (JULES), model description-Part 1: Energy and water fluxes. Geosci. Model Dev. 4: 677-699. DOI:10.5194/gmd-4-677-2011.

Bodine D, Klein PM, Arms SC, Shapiro A. 2009. Variability of surface air temperature over gently sloped terrain. J. Appl. Meteorol. 48: 1117-1141. DOI:10.1175/2009JAMC1933.1.

Clements CB, Whiteman CD, Horel JD. 2003. Cold-air-pool structure and evolution in a mountain basin: Peter Sinks, Utah. J. Appl. Meteorol. 42: 752-768.

Cuxart J, Holtslag A, Beare R, Bazile E, Beljaars A, Cheng A, Conangla L, Ek M, Freedman F, Hamdi R, Kerstein A, Kitagawa H, Lenderink G, Lewellen D, Mailhot J, Mauritsen T, Perov V, Schayes G, Steeneveld G-J, Svensson G, Taylor P, Weng W, Wunsch S, Xu K-M. 2006. Single-column model intercomparison for a stably stratified atmospheric boundary layer. Boundary-Layer Meteorol. 118: 273-303. DOI:10.1007/s10546-005-3780-1.

Davies T. 1976. A lateral boundary formulation for multi-level prediction models. Q. J. R. Meteorol. Soc. 102: 405-418.

Davies T, Cullen MJP, Malcolm AJ, Mawson MH, Staniforth A, White AA, Wood N. 2005. A new dynamical core for the Met Office's global and regional modeling of the atmosphere. Q. J. R. Meteorol. Soc. 131: 1759-1782.

Fuller RM, Groom GB, Jones AR. 1994. The land cover map of Great Britain: an automated classification of Landsat Thematic Mapper data. Photogrammetric Engineering and Remote Sensing 60: 553-562.
Gregory D, Rowntree PR. 1990. A mass flux convection scheme with representation of cloud ensemble characteristics and stabilitydependent closure. Mon. Weather Rev. 118: 1483-1506.

Gudiksen PH, Leone JM, Jr, King CW, Ruffieux D, Neff WD. 1992. Measurements and modeling of the effects of ambient meteorology on nocturnal drainage flows. J. Appl. Meteorol. 31: 1023-1032.

Gustavsson T, Karlsson M, Bogren J, Lindqvist S. 1998. Development of temperature patterns during clear nights. J. Appl. Meteorol. 37: $559-571$.

Haiden T, Whiteman CD, Hoch SW, Lehner M. 2011. A mass flux model of nocturnal cold air intrusions into a closed basin. J. Appl. Meteorol. Climatol. 50: 933-943.

Kiefer MT, Zhong S. 2011. An idealized modeling study of nocturnal cooling processes inside a small enclosed basin. J. Geophys. Res. 116: D20127. DOI:10.1029/2011JD016119.

LeMone MA, Ikeda K, Grossman RL, Rottach MW. 2003. Horizontal variability of $2-\mathrm{m}$ temperature at night during CASES-97. J. Atmos. Sci. 60: 2431-2449.

Lock AP, Brown AR, Bush MR, Martin GM, Smith RNB. 2000. A new boundary-layer mixing scheme. Part 1: Scheme description and single-column model tests. Mon. Weather Rev. 128: 3187-3199.

Mahrt L, Vickers D, Nakamura R, Soler MR, Sun J, Burns S, Lenschow DH. 2001. Shallow drainage flows. Boundary-Layer Meteorol. 101: 243-260.

Mahrt L, Richardson S, Seaman N, Stauffer D. 2010. Non-stationary drainage flows and motions in the cold pool. Tellus A 62: 698-705. DOI:10.1111/j.1600-0870.2010.00473.x.

Manners J, Vosper SB, Roberts N. 2011. Radiative transfer over resolved topographic features for high resolution weather prediction. Q. J. R. Meteorol. Soc. 138: 720-733. DOI:10.1002/qj.956.

McCabe A, Brown AR. 2007. The role of surface heterogeneity in modelling the stable boundary layer. Boundary-Layer Meteorol. 122: 517-534. DOI:10.1007/s10546-006-9119-8.

Neff WD, King CW. 1989. The accumulation and pooling of drainage flows in a large basin. J. Appl. Meteorol. 28: 518-529.

Pepin NC, Seidel DJ. 2005. A global comparison of surface and freeair temperatures at high elevations. J. Geophys. Res. 110: D03104. DOI:10.1029/2004JD005047.

Price JD, Vosper S, Brown A, Ross A, Clark P, Davies F, Horlacher V, Claxton B, McGregor JR, Hoare JS, Jemmett-Smith B, Sheridan P. 2011. COLPEX: Field and numerical studies over a region of small hills. Bull. Am. Meteorol. Soc. 92: 1636-1650.

Schmidli J, Rotunno R. 2010. Mechanisms of along-valley winds and heat exchange over mountainous terrain. J. Atmos. Sci. 67: 3033-3047.

Sheridan PF, Smith SA, Brown AR, Vosper SB. 2010. A simple heightbased correction for temperature downscaling in complex terrain. Meteorol. Appl. 17: 329-339. DOI:10.1002/met.177.

Sheridan PF, Vosper SB, Brown AR. 2013. Characteristics of cold pools observed in small valleys and dependence on external conditions. $Q$. J. R. Meteorol. Soc., doi:10.1002/qj.2159.

Smith SA, Brown AR, Vosper SB, Murkin PA, Veal AT. 2009. Observations and simulations of cold air pooling in valleys. BoundaryLayer Meteorol. 134: 85-108. DOI:10.1007/s10546-009-9436-9.

Thompson BW. 1986. Small-scale katabatics and cold hollows. Weather 41: $146-153$.

Vosper SB, Brown AR. 2008. Numerical simulations of sheltering in valleys: the formation of night-time cold-air pools. Boundary-Layer Meteorol. 127: 429-448.

Whiteman CD, Zhong S, Shaw WJ, Hubbe JM, Bian X, Mittelstadt J. 2001. Cold pools in the Columbia Basin. Weather Forecasting 16: $432-447$.

Whiteman CD, Muschinski A, Zhong S, Fritts D, Hoch SW, Hahnenberger $M$, Yao W, Hohreiter V, Behn M, Cheon Y, Clements CB, Horst TW, Brown WOJ, Oncley SP. 2008. Metcrax 2008-Meteorological experiments in Arizona's Meteor Crater. Bull. Am. Meteorol. Soc. 89: 1665-1680.

Whiteman CD, Hoch SW, Lehner M, Haiden T. 2010. Nocturnal cold-air intrusions into a closed basin: Observational evidence and conceptual model. J. Appl. Meteorol. Climatol. 49: 1894-1905.

Wilson DR, Ballard SP. 1999. A microphysically based precipitation scheme for the UK Meteorological Office Unified Model. Q. J. R. Meteorol. Soc. 125: 1607-1636.

Zängl G. 2005a. Formation of extreme cold-air pools in elevated sinkholes: An idealized numerical process study. Mon. Weather Rev. 133: $925-941$.

Zängl G. 2005b. Dynamical aspects of wintertime cold-air pools in an alpine valley system. Mon. Weather Rev. 133: 2721-2740. 